This item was submitted to Loughborough's Research Repository by the author.

Items in Figshare are protected by copyright, with all rights reserved, unless otherwise indicated.

\title{
Noise source characteristics in the ISO 362 vehicle pass-by noise test:
}

\section{literature review}

PLEASE CITE THE PUBLISHED VERSION

http://dx.doi.org/10.1016/j.apacoust.2013.04.005

PUBLISHER

(C) Elsevier

VERSION

AM (Accepted Manuscript)

LICENCE

CC BY-NC-ND 4.0

\section{REPOSITORY RECORD}

Braun, Michael E., Stephen J. Walsh, Jane L. Horner, and R. Chuter. 2013. "Noise Source Characteristics in the ISO 362 Vehicle Pass-by Noise Test: Literature Review”. figshare. https://hdl.handle.net/2134/12632. 
This item was submitted to Loughborough's Institutional Repository (https://dspace.lboro.ac.uk/) by the author and is made available under the following Creative Commons Licence conditions.

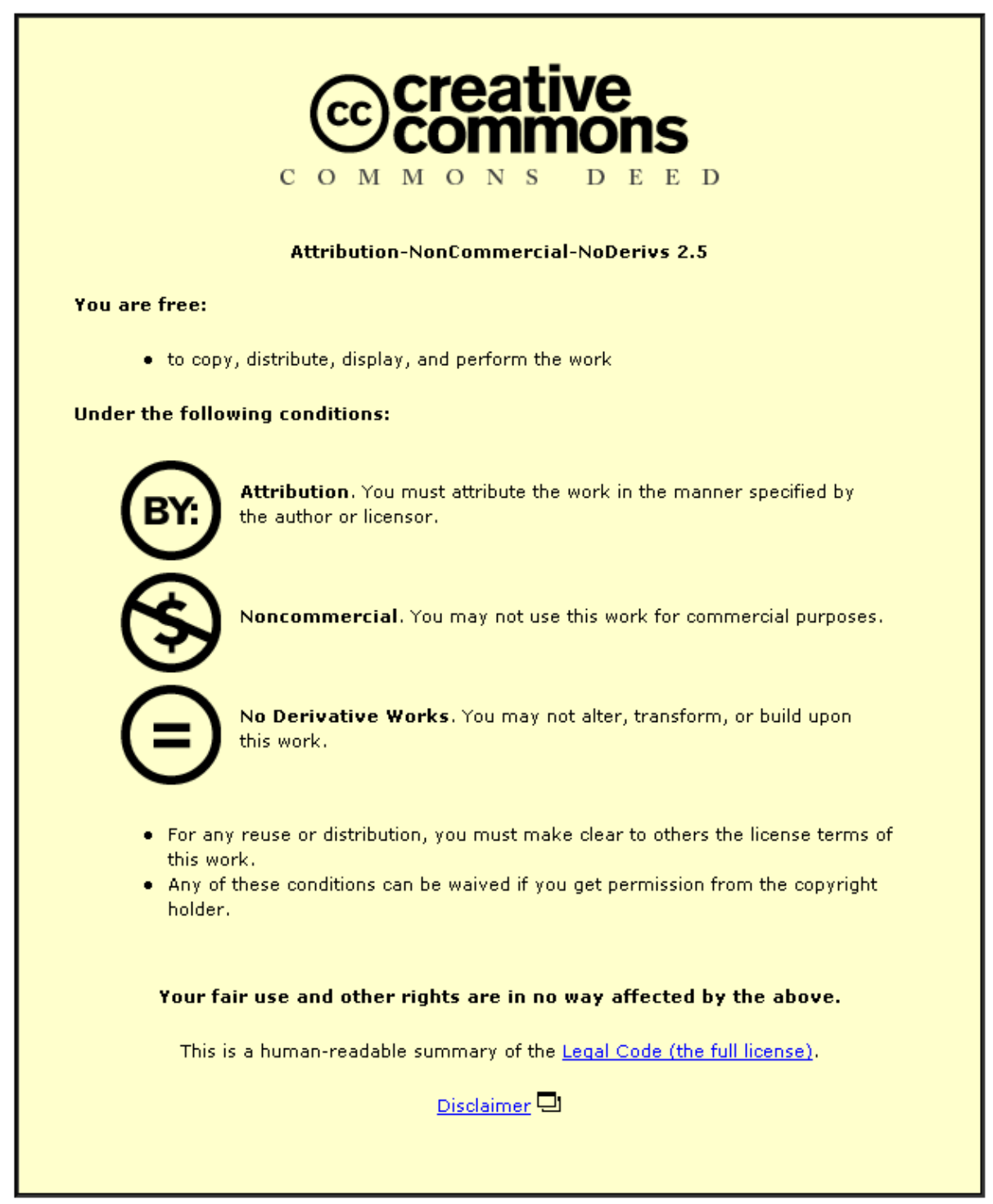

For the full text of this licence, please go to: http://creativecommons.org/licenses/by-nc-nd/2.5/ 


\title{
Noise source characteristics in the ISO 362 vehicle pass-by noise test: Literature review
}

\author{
M.E. Braun ${ }^{a}$, S.J. Walsh ${ }^{a^{*}}$, J.L. Horner ${ }^{a}$, R. Chuter ${ }^{b}$ \\ ${ }^{a}$ Department of Aeronautical and Automotive Engineering, Loughborough University, \\ Loughborough, Leicestershire, LE11 3TU, UK \\ ${ }^{\mathrm{b}} d B(A)$ FAST Ltd., Runcorn, Cheshire, UK \\ *Corresponding author: Tel.: +44 1509 227208. S.J.Walsh@lboro.ac.uk (S.J. Walsh)
}

\section{A B S T R A C T}

Since many people are exposed to road traffic noise in urban areas, current legislation aims to limit vehicle noise emissions. In Europe, the vehicle pass-by noise test is implemented according to the international standard ISO 362. As a result of more recent investigations of urban traffic, a revision to the ISO 362 standard has been proposed that includes a constantspeed test in addition to the traditional accelerated test in order to determine the pass-by noise value. To ensure compliance with the pass-by noise test vehicle manufacturers and suppliers must quantify vehicle noise source characteristics during the design stage of the vehicle. In addition, predictive tools need to be available during the product development phase in order to estimate the final pass-by noise level. In this paper an extensive literature survey is presented of noise source characteristics in the ISO 362 vehicle pass-by noise test. Vehicle pass-by noise is analysed in the time and frequency domains and a ranking of the noise source contributions is established. The characteristics of the four major noise sources (engine, intake system, exhaust system, tyre/road system) contributing to pass-by noise as well as current prediction methods are reviewed.

\section{Keywords:}

Vehicle noise source characteristics; vehicle pass-by noise test; pass-by noise prediction; engine noise; exhaust noise; tyre/road noise

\section{Introduction}

Road traffic noise is a main contributor to environmental noise, which represents a burden to people resulting in annoyance, sleep disturbance or cardiovascular disease [1]. Hence, legislation intends to reduce and limit vehicle exterior noise [2] in order to increase health and life quality. Vehicle exterior noise emission is quantified in terms of idle noise and passby noise with the latter being considered to represent an approximation to typical urban driving behaviour. The international standard ISO 362 represents a guideline for the measurement and calculation of the pass-by noise level for any vehicle class. In the vehicle 
homologation process, it must be verified that the vehicle pass-by noise level is in conformity with present regulations. It is currently being discussed whether to implement a revised test procedure, which reflects urban driving behaviour more realistically, and to reduce pass-by noise limits further. This will result in an increased challenge in the vehicle development process for manufacturers and suppliers.

Comprehensive knowledge about the vehicle noise source characteristics in a pass-by driving manoeuvre is crucial. This paper presents a review of past and current literature. In Section 2 a qualitative overview is given of vehicle noise emissions in the time and frequency domains during the ISO 362 test. Vehicle pass-by noise is composed of the four major noise sources comprising, engine, intake system, exhaust system and the tyre/road system from which a ranking can be established aiming at the identification of the most dominant noise sources. Modifications to these particular noise sources may be the key to achieving vehicle type approval. In Section 3 the characteristics of the major noise sources are analysed as standalone sources and also within the vehicle system. The focus is on noise source phenomena related to the pass-by noise test.

Predictive tools support vehicle engineers at the design stage in order to achieve future compliance with the pass-by noise test. Thus, in Section 4 existing design tools are reviewed. An entirely experimental method is the replication of the pass-by noise test on a chassis dynamometer in a semi-anechoic chamber. Further in-depth analysis of noise source contributions can be carried out through sound pressure measurements in the vicinity of the major noise sources under the pass-by operational conditions and by the determination of transfer path characteristics between each noise source and the pass-by microphones. The combination of both source and transfer path data yields the individual noise source contribution to the overall pass-by noise level, thus, enabling identification of the dominant contributors. Modification of the pass-by noise level is based upon obtaining an optimised transfer path characteristic and a reduced source strength [3]. Numerical simulations of the pass-by noise test do not achieve the same accuracy as experimental methods. However, in the future they may provide an instrument to reduce the number of physical prototypes, thus, lowering development costs and the duration of the product development cycle.

\section{The characteristics of vehicle pass-by noise in the ISO 362 test}

In Section 2.1, the regulations of vehicle pass-by noise legislation are introduced. This is followed in Sections 2.2-2.4 by the analysis of recordings of vehicle pass-by noise levels from the accelerated vehicle test of ISO 362:1998. The information found in the literature differs in terms of the quality of the presented data. Reasons for this can be due to variations in the measurement environment, the measurement procedure or processing errors, vehicles of different type and age, and different types of measurement equipment. Recently developed measurement systems and equipment tend to provide the more accurate recordings. Furthermore, pass-by noise limits have been reduced several times in the past. In Sections 2.2 and 2.3 time history and frequency spectra of pass-by noise tests, respectively, are utilised for the analysis. The contribution of individual noise sources to the overall vehicle pass-by noise as well as noise source ranking is given in Section 2.4. 


\subsection{Introduction to the ISO 362 pass-by noise test}

In Europe, vehicle pass-by noise limits were first implemented in the 1970's. Gradual reductions have been enforced since then. For example, the allowable noise emission of a passenger vehicle has decreased from $82 \mathrm{~dB}(\mathrm{~A})$ to $74 \mathrm{~dB}(\mathrm{~A})$ since the 1970's. This corresponds to a reduction of $84 \%$ or in practical terms, one vehicle emitting $82 \mathrm{~dB}(A)$ is equivalent to the noise emission of six cars at the lower level of $74 \mathrm{~dB}(\mathrm{~A})$. Since vehicles are the source of traffic noise, reducing the contributions of these sources should have resulted in decreased traffic noise. Nevertheless, traffic noise has increased due to higher traffic densities and increased urbanisation. In the development process of a vehicle, manufacturers and suppliers have to ensure compliance with legislation, which has to be verified prior to market launch.

The international standard, ISO 362 [4], from 1998 is the guideline for the implementation of the vehicle pass-by noise test. Its intention is to reflect the noise emission of a vehicle in an urban traffic environment. The test facility consists of a $20 \mathrm{~m}$ by $20 \mathrm{~m}$ acceleration area with a reference line along its centre representing the driving direction of the vehicle. The acceleration area and the driving lane $10 \mathrm{~m}$ prior and after the acceleration area are covered with a tarmac according to the requirements of the standard ISO 10844 in order to ensure equally equipped test facilities. Two microphones are positioned midway in the acceleration area at a distance of $7.5 \mathrm{~m}$ away from the reference line and at a height of $1.2 \mathrm{~m}$. In the case of a passenger car, the vehicle is driven on the reference line approaching the acceleration area at a constant speed of 50 k.p.h. The accelerator is fully engaged when the front of the vehicle reaches the acceleration area, and it is fully disengaged when the rear of the vehicle leaves the area. The maximum A-weighted pass-by noise level is recorded by the two microphones. For the majority of passenger cars with manual transmissions, the pass-by is driven in 2 nd and $3 r d$ gears. Four consecutive runs are carried out for each gear. The measured pass-by noise levels of each gear have to be within a range of $2 \mathrm{~dB}(A)$. They are averaged for each side and each gear from which the highest values of the 2 nd and 3 rd gear are averaged again resulting in the pass-by noise level. This accelerated pass-by test is also the core of the pass-by noise determination of other vehicle classes. During the test, meteorological data have to be within certain tolerance ranges and shall be monitored. High wind speeds and rain prevent the test. The only decision criterion of the pass-by noise test is the maximum A-weighted sound pressure level, sound quality is not an issue.

Despite the reduction of pass-by noise limits over the previous decades, the core test procedure has remained unchanged. It is a common criticism that the test procedure does not reflect typical modern urban traffic conditions. Due to the full acceleration, the pass-by test is dominated by powertrain noise which masks the tyre/road noise contribution [5]. However, urban traffic noise is not dominated by fully accelerating vehicles, thus, the standard has been revised in order to develop a test procedure, which reflects current urban driving behaviour more realistically. After comprehensive observations of traffic noise, a test method is now proposed combining the maximum noise levels of an accelerated vehicle and a constant-speed vehicle pass-by on the same test facility. Gears are selected according to the acceleration capability of the vehicle. In the acceleration pass-by, the speed of 50 k.p.h. 
should be reached when the front of the vehicle reaches the line between the two microphones. In the constant-speed test, the vehicle is driven at 50 k.p.h. From the traffic noise observations, a formula for the calculation of the pass-by noise level was statistically derived, which takes the measured sound pressure and the engine power into account. This pass-by noise level represents the noise emission of a partially accelerated vehicle under urban traffic conditions. Between 2008 and 2010, a comparison database was established containing pass-by noise levels obtained according to both versions of the standard. On average, the pass-by noise level of a passenger car according to ISO 362 (1998) is $72 \mathrm{~dB}(\mathrm{~A})$, which is $2 \mathrm{~dB}(\mathrm{~A})$ higher than the noise level of the suggested new test method [6]. Currently, the implementation of the new test and the adapted noise limits are being discussed. Practically this means that the Council Directive 70/157/EEC and its amendments from the past decades will be repealed. It is proposed to implement the new pass-by noise limits for the European Union in three phases with a limit of $68 \mathrm{~dB}(\mathrm{~A})$ for a passenger vehicle to be reached five years after the publication of the pass-by noise limits [7]. Considering the current wish for a reduction of vehicle exterior noise, it has to be considered that in the future hybrid and electrical vehicles may change the acoustical perception of traffic noise. Such vehicles emit much less noise, of an unfamiliar characteristic, which may cause difficulties, especially for blind people. It may be decided that these vehicles have to emit a minimum noise level in order to raise their acoustical identification potential [7]. However, it is expected that this minimum noise level will still be much lower than the current pass-by noise limits.

\subsection{Pass-by noise versus distance}

Figs. 1-2 [10] present recordings from the left-hand side and right-hand side pass-by microphones of a passenger vehicle in the $2 \mathrm{nd}$ and $3 \mathrm{rd}$ gear tests. The vehicle approaches the entry to the acceleration area, at $-10 \mathrm{~m}$, with constant speed. Thus, the sound is similar to a single noise source approaching a receiver from a far distance. This results in an almost linear increase of the sound pressure level with distance. The sound pressure level of the 2nd gear test has a steeper gradient than the corresponding 3rd gear test once the accelerator pedal is activated at $-10 \mathrm{~m}$. This may be due to the abrupt change in engine load and rapid increase in engine speed, which is associated with greater pressure pulses from the engine and intake system and a greater amount of air taken into the intake system. This would be clearly identifiable in the pass-by noise data in the case of a vehicle with a front mounted engine. The speed difference for the 2 nd gear test is about 16 k.p.h. and for the 3rd gear test, it is approximately 12 k.p.h. Since the vehicle acceleration in 3rd gear is less than in 2 nd gear, the sound pressure gradient in 3rd gear is less steep. In general, higher speed differences over the acceleration area indicate a higher-powered engine. It can be assumed that the noise from the exhaust orifice and the tyres contribute most to the maximum pass-by noise level at $+5 \mathrm{~m}$, since this value occurs after the vehicle has passed the microphone location at $0 \mathrm{~m}$. The influence of attenuation through distance is small due to the relatively short distance between the noise sources and the pass-by microphones. Furthermore, the sound radiation angle between the noise source and the receiver and a transfer path without obstructions leads to higher sound pressure levels. In this position on the test track, the engine noise is screened by the vehicle body and is attenuated by a greater relative 
distance. After the peak level, at $+5 \mathrm{~m}$, the sound pressure level is decreasing in a manner similar to that of a sound source leaving a receiver. According to the inverse square law for a stationary source, the sound pressure is inversely proportional to the distance between sound source and the receiver. However, the pass-by noise measurement data do not exactly show this characteristic as the sound source is moving. Tyre/road noise is considered to be a major contributor in the speed range of the vehicle pass-by noise test. However, two effects may decrease its contribution: (1) the angle between the longitudinal tyre axis and the pass-by microphone, which lessens the horn effect when the receiver is off-axis from the rolling direction; and (2) the attenuation with distance. Coast-by experiments have shown that tyre/road noise gradually increases until the vehicle passes the pass-by microphones, then it decreases with increasing distance between the vehicle and the microphone [8]. Thus, it is assumed that tyre/road noise also contributes to the overall pass-by noise level change with distance shown in Figs.1-2. The measurement variability in the repetition of pass-by runs shown in Figs. 1-2 may occur due to the non-linearities caused by the programming characteristics of the vehicle engine control unit.

Fig. 3 [9] presents the recorded pass-by noise level of a medium class vehicle in 2nd and 3rd gear. The microphone is positioned on the left-hand side of the vehicle. The vehicle starts accelerating at the $0 \mathrm{~m}$ mark and stops accelerating at the $24 \mathrm{~m}$ mark, hence, the vehicle length is $4 \mathrm{~m}$. The sound pressure level change with distance is similar to the previous figures except that the sound pressure level gradient is steeper for the 2 nd gear test up to the $10 \mathrm{~m}$ mark. This characteristic is probably related to the engine or the intake system, since they are closest as the vehicle approaches the microphone. In 3rd gear, the initial increase of sound pressure level with distance is more linear. From the $8.5 \mathrm{~m}$ mark to the $12.5 \mathrm{~m}$ mark, when the engine passes the microphone, the noise level is almost constant. It is assumed that the engine is the dominant noise source in this region of the test. However, the radiation characteristics of the exhaust orifice noise becomes dominant shortly afterwards. For both gears, the exhaust system noise becomes the most dominant contribution at around $17 \mathrm{~m}$. Here, the exhaust orifice is actually at the $13 \mathrm{~m}$ mark and, thus, closer to the microphone than the engine or the intake system and it does not have the screening effects from the vehicle body. Towards the end of the test track, the noise level decreases with increasing distance between the vehicle and the microphone. Thus, from Figs. 1-3, it can be seen that the contribution of each of the four major noise sources depends upon vehicle speed or engine speed, respectively, as well as the vehicle position on the test track, i.e. the distance between the microphone and the specific noise source, as well as the orientation of the major radiation direction of the sound source to the microphone.

\subsection{Pass-by noise frequency content}

Fig. 4 [11] presents a typical recording of an A-weighted pass-by noise level of the lefthand and right-hand side microphones against the position of the front of a passenger vehicle. A scatter band frames the solid curve of sound pressure level. The vehicle speed is also plotted. The diagram originates from the year 1990, which means that different pass-by noise limitations were effective in comparison to 2012. However, the noise characteristic is similar to Figs. 1 and 2. From the experimental data in Fig. 4, the A-weighted pass-by noise 
octave band levels from $125-500 \mathrm{~Hz}$ and from $1-8 \mathrm{kHz}$ are determined and shown in Figs. 56 , respectively. The maximum contribution can be found in the frequency range of $500-$ $2000 \mathrm{~Hz}$. The main contributor in this frequency range is the noise from the tyre/road system. The differences in the pass-by noise levels shown in Figs. 5-6 are due to the different relative contributions of the various noise sources as well as the effect of direct and reflected sound [11]. Analysis of the frequency content of pass-by noise assists in the understanding of noise source characteristics. However, detailed testing of each major noise source is required in order to identify and reduce critical pass-by noise contributions.

Fig. 7 [12] presents three colour map diagrams of different pass-by noise tests taken with a compact class vehicle. The evolution of the spectral content with time during a vehicle pass-by is visualised and helps to indicate individual noise source characteristics and contributions. The plot on the left-hand side, Fig. 7a, is the result of a vehicle pass-by noise test with the engine being switched off and slick tyres in use, thus, only the wind noise is measured. In the middle diagram, Fig. $7 \mathrm{~b}$, the vehicle is equipped with regular tyres, but the engine still remains switched off during the pass-by, which results in a combination of wind and tyre/road noise. There are no specific resonance frequencies, but the increased amplitude components in the frequency range between $500 \mathrm{~Hz}$ and $2 \mathrm{kHz}$ are caused by tyre/road noise [12] and appears to have random noise characteristic. The right-hand side diagram, Fig. 7c, demonstrates the sound pressure frequency spectrum during the normal ISO 362 test. Compared to the middle diagram, Fig. 7b, even higher amplitude components are shown between $500 \mathrm{~Hz}$ and $2 \mathrm{kHz}$, which may be due to the increasing vehicle speed or tyre rotational speed, respectively. Furthermore, higher sound pressure levels can be identified in the high frequency range, $>2 \mathrm{kHz}$. The frequency range below $500 \mathrm{~Hz}$ is dominated by the engine orders, which are related to the sound radiation of the engine, intake and exhaust system [12]. Typical firing or engine orders have their origin in the periodic combustion process of the engine. Due to the aspiration of air and blow-out of exhaust gases, high sound pressure levels at the frequency of the firing orders occurs also at the intake and exhaust systems. The exhaust orifice noise contributes significantly to overall vehicle pass-by noise, especially in the frequency range dominated by the firing orders [13]. Depending upon the vehicle position, the contribution of each noise source varies. The exhaust orifice noise is dominant when the vehicle has passed the microphone position. When the vehicle approaches the microphone, exhaust orifice noise is shielded by the vehicle body. An analogous situation occurs regarding engine and intake system radiated noise when the vehicle is moving away from the microphone. Since only information about the measurement time is given in Fig. 7, it is not possible to relate sound pressure spectrum directly to the vehicle position on the test track, which would have given a better understanding of the local radiation characteristic of the noise sources.

Similar conclusions are obtained from analysis of ISO 362 pass-by noise tests reported in Refs. $[3,14]$. It is concluded that the vehicle noise sources are significantly influenced by engine speed. In general, it appears that the higher the vehicle or engine speed then the higher is the radiated sound. Therefore, the highest sound emission occurs at the highest engine speed. However, the highest engine speed is reached at the end of the acceleration period when the distance between the vehicle noise sources and the microphone is greatest. 
In this case, the radiated sound is attenuated through distance, and the recorded sound pressure level at the microphone location is less than the sound pressure closer to the source. Consequently, the pass-by noise level is dependent on the sound radiation of the noise sources and the distance between the noise sources and the microphone. Thus, the highest pass-by noise level occurs when the combination of sound radiation and distance are most favourable. Furthermore, the shielding of the noise source and the angle between the sound source and the receiver microphone is decisive in determining how much of the noise source emission is detected at the receiver position.

\subsection{Ranking of vehicle noise sources in the ISO 362 test}

Noise isolated vehicles are designed for the identification of noise source characteristics and for the determination of noise source rankings. Different types of noise isolated vehicles have been reported in Refs. $[9,15,16,17]$. In general, a windowing or shielding technique is applied on the vehicle in order to isolate the major noise sources. Usually, the engine is encapsulated with absorption material $[9,16,18]$. The intake and exhaust system noise is attenuated by mufflers with high volumes, which are attached to their orifices $[9,16,18]$. The tyres are either encapsulated with absorption material to minimise their sound radiation [9] or replaced with slick tyres [18]. Each noise source is unmasked in turn, and the pass-by noise levels of each source is measured $[9,18,19]$. In addition, the pass-by noise of the completely unshielded vehicle is recorded in order to determine the overall pass-by noise level and, thus, analyse the relative contribution of each noise source. Such a vehicle could also be used for indoor pass-by noise experiments. A guideline on how shielding techniques are applied on a vehicle is given in Ref. [19].

The relative contributions of the individual noise sources to the overall pass-by noise level is illustrated in Fig. 8 from experiments with a noise isolated vehicle of the middle classification in 2 nd gear [9]. The engine noise contributes most to the overall pass-by noise level. It increases approximately linearly until the front of the vehicle is $1 \mathrm{~m}$ away from the microphone line. The sound pressure level then remains almost constant until it starts decreasing when the front of the vehicle is at the $16 \mathrm{~m}$ mark. Tyre/road noise is the second largest contributor. Its noise level increases until the front of the vehicle reaches the $13 \mathrm{~m}$ mark, it then decreases less steeply. The different gradients of the tyre/road noise levels of the approaching and receding vehicle indicate different noise radiation characteristics from the front and the rear tyre/road combinations. The maximum tyre/road noise level occurs when the rear axle is approximately in line with the microphones, which is probably due to a simultaneous contribution of the front and rear tyres. Since the gradient of the tyre/road noise level of the receding vehicle is not as steep as of the approaching vehicle, the sound radiation of the tyres at the rear axle must be higher than at the front axle. Exhaust orifice noise has a very low impact when the vehicle is in the first half of the test track. After passing the microphone position, the noise level increases significantly until the vehicle leaves the test track area, since the noise can now radiate freely from the tailpipe to the microphone.

Experiments conducted on a high performance sports car [18], on which the noise sources are unmasked in turn, shows the dominance of intake noise in the first half of the 
test track. In the second half of the track the exhaust system is the dominant noise source. Thus, it appears that the relative contributions of the intake and the exhaust systems are interchanged for the first and second half of the test track. Engine and transmission noise are of minor importance. If pass-by noise has to be reduced, measures should be implemented on the most dominant noise sources first $[18,20]$. Experiments with a noise isolated sporting saloon car show that the relative level of each noise source depends upon the position of the vehicle on the test track. At the beginning of the test track, the intake system noise is dominant on the right-hand side microphone. In the middle of the track, when the distance of the vehicle to the microphone is the shortest, powertrain noise is highest. At the end of the track, the exhaust orifice noise is dominant on the left-hand side microphone [18].

Presumably, the intake orifice is installed on the right-hand side of the vehicle and the exhaust orifice on the left-hand side. The overall pass-by noise level in 3rd gear is much lower than in 2nd gear, because the contributions of the engine, intake and exhaust system noise are less. This results in a relatively higher contribution from the tyre/road system in comparison to the other noise sources [18].

Other references report a different noise source ranking for the vehicle pass-by noise test. This is illustrated in Fig. 9 [21], where the noise sources with the highest contributions to pass-by noise are ranked in the following order: tyres, exhaust system, intake system and engine. It can be assumed that different vehicle types having specific design configurations leads to the different order in the rankings. Ref. [21] does not give specific information abouthow these results are achieved. However, it is assumed that the noise levels in Fig. 9 are determined in conjunction with ISO 362. Both Figs. 8 and 9 provide a good qualitative idea of relative noise source contributions and ranking.After establishing a noise source ranking, it is important to analyse the spectral content of each noise source in order to gain a full understanding and, therefore, be capable of reducing pass-by noise [18].

Nearfield Acoustic Holography (NAH) is applied to create Fig.10. Since a stationary noise signal is required in order to carry out $\mathrm{NAH}$, the four-wheel-drive vehicle is set up on a chassis dynamometer in a semi-anechoic chamber and driven at a constant speed of 56 k.p.h., which was found to be the condition with the highest noise emission [15]. A microphone array measures sound pressure at a distance of approximately $0.2 \mathrm{~m}$ from the side of the vehicle. The measurement plane is subdivided into several noise source areas, which can be ranked according to their highest noise levels [15]. In the $1000 \mathrm{~Hz}$ one-third octave band shown in Fig. 10, sound radiation is clearly visible at the exhaust tailpipe and around the tyres. The area between the front and rear axle also shows high sound radiation, which is related to the exhaust system [15]. However, it has to be considered that sound radiation due to the horn effect of the tyres can increase the noise level in that area as well. Presumably, the engine and gearbox also contribute to the sound level around the front tyre, since the sound radiation is less in the area of the rear wheel. NAH seems to be a valuable technique in order to visualise sound radiation during the pass-by noise test. However, no ISO-approved test track surface is used (only the chassis dynamometer) and for this test only one specific condition (i.e. noise radiation at 56 k.p.h.) is analysed. Nevertheless, a pass-by noise level is calculated for the ISO 362 microphone location, which only deviates $0.2 \mathrm{~dB}$ from the measured pass-by noise level on the test track [15]. 


\section{Vehicle noise source characteristics and their influence on pass-by noise}

Details about each of the major noise sources such as the engine, intake system, exhaust system and tyre/road system are given in this section. As well as a brief description of their stand-alone characteristics, the noise emission from each noise source within the vehicle system in the ISO 362 pass-by noise test is also described.

\subsection{Engine noise}

Diesel engines usually emit higher noise levels than petrol engines at the same engine speeds [9], which is caused by the higher in-cylinder pressure excitations [22]. The higher the engine speed then the higher are the noise emissions. At its highest rotational speed, the petrol engine reaches the same noise level as that of Diesel engines [9].Radiated engine noise depends on the in-cylinder pressure characteristics during the combustion process, i.e. the mechanically and flow induced noise [22]. The noise from the bottom of the engine can contribute significantly to the overall noise radiation [3].

An engine noise map is presented in Fig. 11 [9] in which the radiated sound pressure level of an engine is plotted versus torque and rotational speed. In general, sound pressure level increases with rising engine speed. Sound pressure level increases with rising torque only at low engine speeds and remains relatively constant for a given higher engine speed. An accelerated pass-by in 2nd gear covers an engine speed range between 3000 r.p.m. and 4500 r.p.m., and between 2000 r.p.m. and 3000 r.p.m.in 3rd gear [3]. Considering the range of engine speeds encountered during the pass-by noise test, it is possible to estimate the radiated sound pressure levels from the engine during the pass-by noise test. However, differences in radiation on each side of the engine as well as the attenuation properties of the vehicle body have to be taken into account.

Figs. 12-13 [23] provide a visualisation of the noise emission for an engine mounted in the vehicle, which illustrates about sound radiation characteristics of the engine in the pass-by noise test. Figs. 12-13 are the result of the application of moving frame acoustic holography (MFAH) on a pass-by test under ISO 362 conditions. Therefore, a microphone array is positioned very close to the passing vehicle midway on the ISO 362 test track. The measurement duration is less than half a second, since this method requires a quasistationary condition, i.e. the vehicle speed is approximated as constant and frequency changes are neglected. The sound pressure distribution in the measurement plane for the 2nd $(120 \mathrm{~Hz})$ and 3rd $(180 \mathrm{~Hz})$ harmonic of the firing frequency, respectively, are shown in Figs. 12-13.All noise sources besides the engine are noise isolated. It can be seen that the sound from the engine radiates from underneath the vehicle into the environment. It can be assumed that the vehicle body causes reflections and diffractions. It also shields the directly radiated engine noise from the engine compartment, since there is no visible sound radiation from this region in either figure. Moving source beamforming also appears to be a suitable tool for the visualisation of the noise emissions of moving vehicles [24]. However, detailed work about the application of this method for the analysis of pass-by noise source characteristics has not been published. 


\subsection{Intake and exhaust system noise}

The intake and exhaust systems represent noise sources of similar characteristics, which contribute significantly to vehicle exterior noise. A brief historical overview is given in Ref. [19]. Until the 1960s, exhaust tailpipe noise was the dominant source for vehicle exterior noise. Due to noise limiting legislation and the application of large volume mufflers, noise levels were reduced in the following years. However, this unmasked intake system noise, which has become the most significant noise source at full load from around 1980 onwards. Port fuel injection technology and the application of plastic intake manifold, instead of steel, in combination with silencing elements has lowered intake system noise. Overall intake and exhaust system noise are on a similar level today to the engine and tyre/road noise. However, intake and exhaust system noise contributes significantly, if the engine runs under high load [25]. Sports cars present an exception with exhaust system noise being up to $20 \mathrm{~dB}$ higher than intake system noise under full load conditions in order to sharpen the subjective perception of the vehicle [13]. Nonetheless, these noise emissions have to comply with current legislations.

Intake and exhaust system noise can be categorised into primary and secondary noise sources [19]. Primary noise sources are the pressure pulses, which are caused by the opening and closing events of the engine valves. The pulses advance through the intake and exhaust system to the orifices, where they radiate as noise into the environment. Since the valve motion is related to the engine combustion rate, intake and exhaust system noise occurs at the engine firing frequency and its multiples depending on the specific design [25]. The mass flow moving inside the intake and exhaust system is considered to be the secondary noise source. The so-called flow noise is caused by turbulence and vortices of the high speed mass flow around sharp edges, small bends and free jets [25]. The opinions about its characteristic are different. According to Ref. [25], flow noise is of a broadband character between $1 \mathrm{kHz}$ and $3 \mathrm{kHz}$. In contrast, it is described in Ref. [19] as of a rather tonal character with low and high frequency components.

Shell noise can be seen as another noise source, although its contribution to pass-by noise is relatively minor nowadays. Large plane surfaces, for example, the air filter box, manifolds and mufflers are likely to radiate shell noise. Noise control measures are to increase the stiffness of the structure with ribbing, pressed muffler shells or two layers of thin sheet-steel walls in order to shift the resonant frequency of a particular structure above the main excitation frequency [25]. Ref. [3] notes that the exhaust muffler surface can contribute occasionally to pass-by noise.

Both intake and exhaust systems can be tuned to either attenuate or emphasise specific frequency content. The radiated noise at the orifices is dependent upon the acoustic properties of the ducts and the reactive and resistive mufflers. Uneven pipe lengths from different cylinder banks and uneven firing sequences result in the generation of half engine orders. Reactive mufflers, such as expansion chambers, quarter-wave and Helmholtz resonators, initiate reflections of the moving pressure wave in order to change its phase and, hence, use phase cancellation as an attenuation measure [25]. Resistive mufflers filled with absorption material like fibreglass or mineral wool decrease the wave amplitudes through 
absorption. They are predominantly applied in the exhaust system to lower broadband noise and are generally more effective in the high frequency range [25]. The air filter box of the intake system can also be designed as a resistive muffler. It is assumed that the compressor housing has the properties of a reactive silencer element and, thus, it can lower intake noise [19]. Ref. [13] reports that high turbulence in the compressor attenuates predominantly the sound pressure amplitudes of the engine orders. However, the compressor and the turbine are also noise sources. Stall on the blades causes broadband noise at 1-4 kHz; imbalance of the turbocharger shaft and pressure pulses within the turbocharger creates tonal noise, which is known as 'whining' noise; the rotational noise of the compressor and turbine blades occurs between 4-14 kHz due to pressure differences on the intake and exhaust side, and is known as 'whistling' noise $[13,26]$. The generated noise is radiated from the turbocharger housing or transmitted to the adjacent parts of the intake and exhaust systems. Additional reactive measures may be necessary, for example, an air intercooler can function as a broadband attenuator [13]. The acoustic performance of resistive mufflers increases with the appropriate absorber density. However, this should not result in higher weight, which is not desired in terms of costs and fuel consumption. It is usually attempted to avoid any measure resulting in significantly higher back-pressure in the exhaust system, since this leads to reduced engine power. Flow noise can be reduced by the application of large diameter pipes, which decrease flow velocity, and by the avoidance of sharp edges and bends which, thus, provides smoother flow conditions [25].

The frequency spectrum of intake orifice noise features the characteristics of primary and secondary excitation noise sources, as illustrated in Fig. 14 [13]. High amplitude noise due to the engine orders can be identified as well as flow noise, which affects almost the whole engine speed range. It appears that a broad frequency band above $400 \mathrm{~Hz}$ is excited by flow noise, with frequency ranges around $450 \mathrm{~Hz}, 600 \mathrm{~Hz}$ and $820 \mathrm{~Hz}$ having the highest amplitudes.

The noise characteristic or perceived sound quality of the exhaust system affects the recognition of a vehicle by customers [25]. Therefore, target values are agreed very early in the vehicle development process. Additionally, exterior noise regulations regarding idle and pass-by noise have to be adhered to, which can potentially counteract with powertrain performance requirements [25]. In contrast to the intake system, the flow in the exhaust system is considered to be much more influential due to the higher flow speed [19]. In addition, temperature gradients are much higher, and back-pressure has a greater impact on engine performance than wave motion in the manifold [19]. Flow noise is often amplified in the complex structure of a silencer [27].

Typical exhaust tailpipe noise emissions are shown in the waterfall plot of Fig. 15a [28]. The 2nd engine order dominates up to about 3500 r.p.m. as can also be seen in Fig. 15c [28] with the unweighted Decibel scale. Flow-induced noise can be detected at higher engine speeds over a broad frequency range. According to Ref. [29], flow noise has a decisive influence on the overall sound pressure level of the exhaust orifice. Considering the engine speed range during the pass-by noise test, from approximately 3000 r.p.m. to 4500 r.p.m. in 2nd gear [3], flow noise can contribute significantly to the pass-by noise level. 
The results of a one-dimensional Computational Fluid Dynamics (1D CFD) simulation, which is valid for frequencies below $1 \mathrm{kHz}$ [29], shows good agreement regarding engine orders between the measured and simulated data. However, flow noise is not taken into account, which represents a weakness of the simulation. Current commercial software products offer a method to estimate the sound power level caused by flow noise at the exhaust orifice [30]. The applied flow noise model uses atmosheric pressure, exhaust gas temperature and velocity at the exit as well as the pipe diameter of the exhaust orifice [30]. The model needs to be calibrated and cannot calculate flow noise at specific frequencies [30]. If 1D CFD simulation is to be used for pass-by noise prediction, then flow noise, reflections from the vehicle and ground, as well as the instantaneous distance between the source and receiver will also need to be considered.

To determine the measurement results shown in Figs. 16-18, an engine is set up in a sound-proofed chamber and the exhaust pipes are led outside [31]. The exhaust orifice is about $3 \mathrm{~m}$ away from a wall and $1.8 \mathrm{~m}$ above ground [31], which means that the sound is radiated into a relatively free space where reflections are negligible. Fig. 16 illustrates that the exhaust orifice under full load produces higher sound pressure levels than under the no load condition. A-weighting of the frequency spectrum leads to a significant reduction in the sound pressure level especially in the lower to mid engine speed range. In the high engine speed range, the difference between linear and A-weighted sound pressure level remains rather constant.

Fig. 17 shows a typical frequency spectrum of exhaust noise measured at 1880 r.p.m. The high amplitude components in frequency range up to $1000 \mathrm{~Hz}$ dominate the noise spectrum. High sound pressure amplitudes can be identified at discrete frequency components, which are multiples of the firing frequency. This illustrates that exhaust noise at lower frequencies is mainly caused by the working cycle of the internal combustion engine, and the contribution from flow noise is marginal in this case [31].

The radiated sound characteristics of an exhaust tailpipe are measured and presented in two scenarios in Fig. 18 [31]: Fig. 18a shows the relative sound pressure level on a $\pm 135^{\circ}$ circular arc around the orifice at $0.9 \mathrm{~m}$ distance and Fig. 18b along a radial path at an angle of $45^{\circ}$ to the tailpipe. The relative change in sound pressure level is plotted against angular position (Fig. 18a) or distance from the outlet (Fig. 18b) for two non-dimensional frequencies $k a$, where $k$ is the acoustic wave number and $a$ is the pipe radius. Higher-order modes in circular ducts are cut-off for values of $k a<1.84$ [32]. The two ka values of 0.15 and 0.7 are well below this limit, hence, the influence of higher-order modes is assumed negligible. In Fig. 18a, the sound pressure level varies significantly depending upon the angle on the arc. For $k a=0.15$, the relative sound pressure level has a rather smooth characteristic. However, its amplitudes are higher in front of the tailpipe, i.e. $0^{\circ}$, and decrease towards the larger angles. Sound pressure increases again after the $+90^{\circ}$ mark. For $-90^{\circ}$ to $-135^{\circ}$, the sound pressure is approximately constant. For the non-dimensional frequency $k a=0.7$, the relative sound pressure level has relatively small amplitude fluctuations in the region $\pm 25^{\circ}$. In the region $+25^{\circ}$ to $+135^{\circ}$ high amplitude fluctuations of up to $6 \mathrm{~dB}$ occur, whereas the relative sound pressure level remains approximately constant in the region $-90^{\circ}$ to $-135^{\circ}$. Different characteristics between $+90^{\circ}$ and $+135^{\circ}$ and $-90^{\circ}$ to $-135^{\circ}$ can be identified in both ka plots. 
Certain level variations exist, but for the thorough analysis of the directivity pattern of exhaust orifice noise more measurement data are required from several distances around the orifice. In Ref. [31] a spherically diverging sound wave from the orifice is assumed. In Fig. 18b,the trace of radiated sound pressure is in conformity with the inverse square law of acoustics. Although, fluctuations appear for the $k a=0.7 \mathrm{plot}$, the trend follows the theoretical decline of sound pressure. The higher non-dimensional frequency measurement $k a=0.7$ has the higher fluctuations in relative sound pressure level in both measurement scenarios. These fluctuations may be caused by turbulent activity in the exhaust gas flow. The effect of evanescent modes at the end of the exhaust may become noticeable for $k a=0.7$ causing increased sound pressure fluctuations.

It can be summarised that exhaust orifice noise is dependent on engine speed, load and the design of the exhaust system (since the exhaust system consists of several noise sources when gas flows through its pipes of different lengths and cross sections, as illustrated in Fig. 15b. Exhaust orifice noise appears to radiate sound in a spherical direction according to the inverse distance law. The frequency range of interest is up to approximately $1 \mathrm{kHz}$.

Noise from the exhaust tailpipe orifice is one of the main contributors to overall pass-by noise. The exhaust orifice noise or jet noise is caused through the mixing of ambient air with the exhaust gas flowing out of the exhaust orifice at high velocity [33]. The exhaust gas jet consists of the potential core region and the turbulent mixing region of the exhaust gas and ambient air. High frequency noise with a high sound pressure level is generated by small vortices; larger vortices cause lower frequency noise with a lower sound pressure level. The frequency spectrum of jet noise is characterised by a broad-band random noise. The exhaust jet flows of two different types of silencer are analysed in Ref. [33]. The shape of the jet flow and its velocity profile are influenced by the structure of the tailpipe, for example, whether sintered or solid metal [33]. The velocity profile of a sintered metal tube is not as wide as that of a conventional exhaust tube due to the different friction properties between the gas and the pipe wall as well as the higher gas permeability including a heat loss through the sintered metal tube [33]. The width of the jet flow depends upon the engine speed, for example, the higher the engine speed, the wider is the jet flow [33]. It is assumed that a smaller jet width provides a smaller turbulent mixing region and, thus, reduced noise radiation.

The flow pattern downstream of a pipe orifice and its related noise is experimentally investigated in Ref. [34]. In the experiment, compressed air is released into a pipe simulating the exhaust system. Schlieren pictures show a high pressure wave leaving the orifice, which can develop into a shock wave depending upon the speed of the exhaust valve. In order to analyse the far field, sound pressure measurements are conducted at $1 \mathrm{~m}$ distance from the pipe orifice at angles of $15^{\circ}, 30^{\circ}, 45^{\circ}$ and $60^{\circ}$ to the measurement line of the extended pipe axis. For different low to high exhaust valve speeds, the highest sound pressure amplitude occurs at $30^{\circ}$ followed by the angles of $15^{\circ}, 45^{\circ}$ and $60^{\circ}$, respectively.

Source models for the prediction of exhaust orifice noise in the vehicle pass-by noise test are developed in Ref. [35]. Based on experiments, two source models are implemented to cover exhaust discharge noise. The first point source model is located at the exhaust orifice and covers the pulsation noise component up to $500 \mathrm{~Hz}$, i.e. pressure pulsations originating 
from the opening and closing of the exhaust valves. The second point source model is located at 2.5 times the orifice diameter downstream of the exhaust orifice and covers the jet noise component over $500 \mathrm{~Hz}$. The predicted values show a good agreement with measured values for the departing vehicle, when the transfer path between the exhaust orifice and pass-by microphone is not shielded by the vehicle body. When the vehicle approaches the pass-by microphone, deviations occur, which may be due to insufficient fidelity in the description of the noise source directivity, or the omission of diffraction and reflection of sound from the vehicle body and the track surface in the model.

\subsection{Tyre/road noise}

Tyre/road noise has not been reduced as much as powertrain and exhaust system noise over the recent decades [13]. Thus, it remains a significant contributor to overall pass-by noise. The generation mechanisms for tyre/road noise are complex but can roughly be divided into structure-borne and air-borne related mechanisms. Impact mechanisms, for example, the impact of the road surface pattern on the tyre surface, and adhesion mechanisms, for example the stick/slip effect between tyre tread element and the road surface, are assumed to generate structure-borne noise. Air displacement mechanisms, for example the pumping effect of air in pockets between the tyre tread and the road surface, are responsible for air-borne noise. The contribution of each mechanism to overall tyre/road noise varies depending upon the tyre type and size, the road and pavement construction and the vehicle operating condition [8]. Although the tyre radiates sound, the effect of the road structure must not be neglected. Tyre/road noise is a result of the interaction between the tyre and the road. The noise sources which mainly contribute to the overall A-weighted noise level, are located close to the tyre contact patch at or in the vicinity of the leading and trailing edges and at the sidewall [8]. Amplification mechanisms like the horn effect, the effect of different acoustical and mechanical impedances, and the tyre structural and acoustical resonances have an influence on the radiation and transmission of tyre/road noise to a receiver [8]. The horn effect is considered to be the most influential among these mechanisms, and, thus, can have a decisive contribution to the pass-by noise level.

The horn effect of a single tyre resting on the ground and of a tyre mounted to a vehicle is analysed in Refs. $[8,36]$.The geometrical boundary of the acoustical horn is defined by the leading or trailing edge of the tyre and the road surface. It is suspected that the matching of the acoustic impedance in the 'horn' and the ambient acoustic impedance provides favourable conditions for the amplification of sound radiation [8]. Conducting reciprocity measurements on a single tyre with a loudspeaker positioned at $1 \mathrm{~m}$ distance to the tyre and with the microphone in line with the tyre plane, an amplification of up to $23 \mathrm{~dB}$ at a distance of $10 \mathrm{~mm}$ off the contact patch trailing edge of the tyre and the road is reported [36]. It is concluded that the horn effect is greatest at the location closest to the contact patch trailing edge. The effect is greatest in the frequency range from $1-5 \mathrm{kHz}$ with maximum amplification between $2-3 \mathrm{kHz}$. The analysis of the angular properties of the horn effect shows that the sound radiation decreases when the receiver moves from the in-line plane of the tyre to a position perpendicular to the tyre plane. The angular acoustic properties change, if the measured sound pressure values are corrected for distance attenuation, thus, simulating a 
coast-by situation of the tyre with respect to the receiver position at $7.5 \mathrm{~m}$ distance and $1.2 \mathrm{~m}$ height to the centre of the tyre [36]. The interaction between distance attenuation and the horn effect leads to a maximum amplification between the angles of $45^{\circ}$ and $75^{\circ}$ off the tyre plane in the frequency range around $1000 \mathrm{~Hz}$. This can have a high influence on pass-by noise, since the pass-by noise level is determined using frequency A-weighting. The previous measurement arrangement is also carried out with the tyre mounted on a vehicle [36]. The overall amplification due to the horn effect at the receiver position is higher than without the vehicle body. Maximum amplification occurs again at angles between $45^{\circ}$ and $75^{\circ}$. In particular, the low frequency range, $<400 \mathrm{~Hz}$, shows a significant increase. Thus, sound reflections from the vehicle body and the ground contribute to the response in a manner which does not occur in the single tyre experiments. The amplification differs by only $2 \mathrm{~dB}$ for angles between $45^{\circ}$ and $90^{\circ}$. However, the amplification in the tyre plane is lower, which might be related to the screening effect of the vehicle body. Thus, a shorter distance between the noise source and the receiver in conjunction with those angles at which the influence due to the screening effects of the vehicle body is smallest provides the most favourable conditions for the highest contributions to vehicle pass-by noise [36].

Tyre/road noise radiation is not omni-directional, rather it exhibits a certain directivity. The directivity pattern can be divided into horizontal and vertical directivity. Fig. 19 [8] represents an example of the horizontal directivity of tyre/road noise. The third-octave band frequency spectrum of a standard tyre, which is tested on a dynamometer outer drum with a special replication of a road surface, is shown. The sound radiation of frequencies up to $1000 \mathrm{~Hz}$ occurs predominantly at the front of the tyre $\left(0^{\circ}\right.$ or $\left.360^{\circ}\right)$, whereas higher frequencies (1.5$8 \mathrm{kHz}$ ) radiate relatively more towards the rear $\left(180^{\circ}\right)$. In general, sound radiation at the front of the tyre is slightly higher than at the rear. The sound radiation perpendicular to the tyre plane is rather small in comparison to the forward and aft directions. The sound radiation of tyre noise in the vertical direction is especially affected by the vehicle body. An indication about vertical directivity is given in Ref. [37]. Measurements are conducted on a public road with an average vehicle speed of 90 k.p.h. Sound pressure is recorded to the side of the vehicle and at different heights above the road. The results indicate a constant level of sound radiation between the road and a vertical angle of $45^{\circ}$. Above this angle, the sound radiation declines by approximately $3 \mathrm{~dB}$ until it reaches a constant level at a given height above the vehicle, which is due to the screening effect of the vehicle body. Clearly, both the horizontal and vertical directivity of tyre noise will have an influence on pass-by noise.

Due to the acceleration process in the pass-by noise test, the drive wheels experience high acceleration, torque and slip. Furthermore, a weight displacement towards the drive axle results in higher vertical loads on the drive wheels. The sound intensity level of a tyre/road system rises with increasing acceleration [8]. Increasing torque results in higher tyre/road noise at 30 k.p.h. [38]. Trailer measurements of a summer tyre on an asphalt concrete road show an increase in sound pressure level of about $20 \mathrm{~dB}(\mathrm{~A})$ at a velocity of 50 k.p.h., if the slip increases by up to $10 \%$ [8]. For higher slip values, the noise level remains approximately constant [8]. A study [39] about the influence of vertical load on tyre/road noise finds increasing sound pressure levels for increasing vertical loads up to $3000 \mathrm{~N}$ in the velocity range of 50 k.p.h. to 70 k.p.h. For higher loads up to $5000 \mathrm{~N}$, the sound pressure levels 
decrease slightly in general. However, the sound pressure level for $5000 \mathrm{~N}$ at 50 k.p.h. represents an exception, since it is the maximum value for that particular speed value.

Vehicle deceleration can be used instead of acceleration in order to recreate the contribution of torque to tyre/road noise. Ref. [8] notes that there is no difference in the noise level for an accelerated or a braked tyre [8]. Thus, in Ref. [12] tyre/road noise measurements are conducted on a decelerating vehicle fitted with different tyre types. Fig. 20 [12] displays waterfall plots of the noise from a wide summer tyre, a regular summer tyre and a slick tyre. Since the tyres are mounted on the vehicle, the measurements take into account the influence of the vehicle body on the tyre/road noise radiation. Measurements are conducted with the engine being switched off and the vehicle braked so as to have a deceleration, which is equal to the negative value of actual acceleration during the ISO 362 test, in order to recreate analogous torque condition when measuring only tyre/road noise. For the wide summer tyre, the dominant frequency range is $200-1000 \mathrm{~Hz}$, whilst for the regular summer tyre the dominant frequency range is between $500 \mathrm{~Hz}$ and $1 \mathrm{kHz}$. For the slick tyre, the radiated noise level is much lower and there is no dominant frequency range. It is concluded that the wider is the tyre, the higher are the noise levels and the larger is the dominant excited frequency band.

The conducting of cruise-by noise measurements for cars over a speed range from $40-$ 100 k.p.h. according to the Statistical Pass-By (SPB) method shows a linear relation between the measured sound pressure level and the vehicle speed on a logarithmic scale [8]. The noise level varies from 69-78 $\mathrm{dB}(\mathrm{A})$ over a speed range from 50-70 k.p.h. The SPB method measures the noise of single vehicles on regular roads at constant speed. The distance between the microphone and the driving lane is $7.5 \mathrm{~m}$. A regression line visualises the relation of noise and speed. The exact tyre type or vehicle type is unknown, however, vehicles are classified into general categories. The noise level for heavy vehicles is higher than for cars and the noise-speed relation is not entirely linear for the lower speed range. Although, the SPB method is carried out on public roads, it indicates the dimension of passby noise levels to expect in the pass-by noise test.

The moving frame acoustic holography (MFAH) method is applied in order to analyse vehicle tyre sound radiation under different pass-by conditions [23]. Figs. 21-23 illustrate the effect of different driving conditions on radiated tyre/road noise: accelerating condition according to ISO 362 (Fig. 21); constant speed condition (Fig. 22); and coast-down condition (Fig. 23). A vehicle with reduced noise radiation and special tread pattern tyres on the measurement side is used, whilst smooth tyres are installed on the opposite side. The special tread pattern tyre is designed to radiate sound in a narrow frequency band around $500+/-5 \mathrm{~Hz}$ at a vehicle speed of 55 k.p.h. It is not known, if the front or rear axle is driven. Figs. 21-23 illustrate the sound pressure distribution in the measurement plane parallel with the side of the vehicle. Sound pressure recording lasts less than $0.5 \mathrm{~s}$ and is taken when the vehicle passes the microphone array. During this short period of time, vehicle speed is assumed to be constant and frequency changes are neglected in order to apply MFAH .The three frequencies analysed in Figs. 21-23 cover a similar frequency range. From Figs. 21-23 it can be seen that a noise source is located at the rear of the front tyre and its location remains relatively unchanged regardless of the driving state. Viewing all driving conditions, it 
can be seen that the sound source location at the rear of the rear tyre moves towards the tyre contact patch when the drive force is less. The noise source amplitudes vary due to the driving condition. Noise sources are approximately equal in strength for the front and the rear axle in the accelerating condition. For the constant speed condition, the noise source at the front tyre is dominant and for the coast-down condition, the noise source at the rear axle shows the highest amplitudes. It is concluded that tyre/road noise depends on the driving state, which includes force transfer in the tyre contact patch, tyre vibrations, oscillating air cavities, etc. Furthermore, an area of high sound pressure can be identified between the front and rear axle for the driving state of constant velocity. This is due to interference effects between sound radiation from the front and rear tyre [23].

The propagation of noise in the far field is illustrated by using sound intensity measurements in a plane $0.5 \mathrm{~m}$ above the ground in Fig. 24. The noise sources identified in Figs. 21-23 can now be identified at the origin of the abscissa shown in Figs. 24b-d. From Figs. $24 b-d$, the sound intensity into the far field can be visualised up to the z-coordinate value of $7.5 \mathrm{~m}$. Sound spreads out from the noise sources in different directions away from the vehicle. The noise level decays along the abscissa and at $7.5 \mathrm{~m}$ distance, the noise level is reduced significantly compared with the MFAH measurement surface at $z=0$. The accelerating condition exhibits higher intensity levels than the constant-speed and coastdown conditions. The constant-speed condition is heavily influenced by the interference effect between the radiated sound from the front and rear tyres. Due to the interference effect a strong directivity between the axles points perpendicularly away from the side of the vehicle. All three driving conditions are important for the analysis of vehicle pass-by noise. The accelerating and constant speed conditions are both implemented in the revised version of ISO 362 from 2007. The coast-down condition is often used to determine the contribution of tyre/road noise to the overall pass-by noise levels.

\section{Existing methods for the prediction of vehicle pass-by noise}

The aim of predictive methods for the vehicle pass-by noise test is versatile. The basic objective is the prediction of the maximum A-weighted sound pressure level as an indication of whether the ISO 362 pass-by noise test can be passed. However, a more in-depth analysis of the evolution of exterior noise may be desirable. Certain methods allow contribution analysis of the vehicle noise sources enabling identification of critical noise sources. Predicted pass-by noise can be analysed against track position or evaluated in the frequency domain at discrete positions on the test track. Distinctive features of the methods are experimental or numerical, indoor or outdoor, complete vehicle test or system based tests. Predictive methods can combine one or more of these features.

The indoor simulation of the pass-by noise test with microphone line arrays aims at providing similar test conditions without any environmental restrictions. The indoor or outdoor experimental determination of the strength of the major exterior noise sources and their corresponding airborne transfer functions gives details about each source contribution to the overall pass-by noise. Numerical techniques intend to replicate the real pass-by noise virtually, thus, making the design process less dependent upon physical prototypes. The following sub-sections contain a detailed overview about these techniques. 


\subsection{Indoor simulation of pass-by noise with microphone arrays}

Large semi-anechoic chambers with chassis dynamometers provide an alternative test environment to traditional outside pass-by noise experiments. For any indoor simulation of pass-by noise, it is generally advisable to provide similar test conditions as are required in the standard ISO 362. This decreases systematic measurement errors and approximates the experimental result of the real pass-by noise test more accurately.

A vehicle is positioned centrally on a chassis dynamometer within a semi-anechoic chamber, which provides approximately free-field conditions over a reflective plane. A large chamber provides enough space to cover the square between the lines of AA' and BB' of the pass-by noise test. Microphones are arranged in a line array on both sides of the vehicle at a distance of $7.5 \mathrm{~m}$ to its centre line and at a height of $1.2 \mathrm{~m}$. The spacing between microphones is either constant, for example $1 \mathrm{~m}$, or varying with a smaller spacing where the highest noise levels are expected [14,40]. The number of microphones depends on the spacing and the size of the chamber, for example Ref. [14] reports 15 microphones per side and Ref. [40] reports 19 per side. The speed and load conditions of the real pass-by test are simulated by means of the chassis dynamometer enabling acceleration or constant-speed driving conditions, while sound pressure is recorded by the microphones. The indoor simulation can be run fully automatically and is well controlled, which provides good experimental repeatability, which cannot always be achieved by a driver in road tests $[14,40,41]$. Since the vehicle and microphones are stationary, an inverse approach has to be applied in order to estimate the pass-by noise level against track position from the sound pressure recordings of each microphone [14]. Basically, the microphones in the front of the vehicle determine the pass-by noise when the vehicle 'enters' the test track, while the microphones behind the vehicle determine pass-by noise when the vehicle 'leaves' the test track. Estimates of the vehicle speed obtained from the chassis dynamometer combined with engine speed measurements enable the determination of the theoretical vehicle position on the test track [14]. Depending upon the vehicle's 'position', the relevant microphone signals are selected, data interpolated between adjacent microphones and then connected in series. The transitions between adjacent microphone signals are smoothed to avoid leaps and discontinuities in the overall signal. Coherent and incoherent parts of the signal are treated with different algorithms [14,42]. Finally, a filter is utilised to account for the Doppler frequency shift of a moving noise source [14]. The resulting signal is an estimate of a timedependent pass-by noise signal [14,41], which can also be utilised in subjective listening test for in-depth jury testing and psychoacoustic analyses [14].

In cases where large semi-anechoic chambers are not available, however, the indoor simulation of the pass-by noise test can be carried out in smaller rooms, if certain correction measures are applied. The microphone line array has to be positioned in the acoustic farfield of the vehicle, but the distance between the microphone line array and the vehicle centre line can be less than $7.5 \mathrm{~m}$. A correction based on the inverse square law is applied to estimate the sound pressure at $7.5 \mathrm{~m}[14,41]$. The necessary assumption for this procedure is that the radiated noise originates from a single point, which is termed the acoustic centre. It is assumed to be located on the ground within vehicle dimensions and it may be dependent 
on frequency and driving condition [14,41]. The acoustic centre is not a fixed location, but can be moved during the pass-by simulation to improve the correction procedure. The acoustic centre is determined by the highest sound pressure reading of the sideline microphones which cover the vehicle length. Vehicles with front engine tend to have the acoustic centre in the middle of the vehicle, since the exhaust orifice noise is a major noise contributor in addition to the engine noise. The acoustic centre moves to the rear of the vehicle for a rear mounted engine [14]. The length of certain test chambers may be too small, making it impossible to cover the measurement angle with the microphone line array. The measurement angle is the maximum angle between the vehicle entering the test track and the ISO 362 pass-by microphone. Hence, the microphones can be positioned outside of the line array in order to cover the whole angle area [14]. The acoustic centre can be considered as an idealisation. However, it cannot represent the origin of the sound radiation of all vehicle noise sources. Nevertheless, the systematic error resulting from the utilisation of the small room is reduced by the correction procedure [14].

The accurate replication of tyre/road noise on the drum of the chassis dynamometer is related to the replication material and its surface structure; the drum curvature appears to be of less influence [43]. The non-driven wheels of a vehicle are usually blocked, if only one chassis dynamometer is available. Thus, the contribution to rolling noise of these tyres is neglected. Slick tyres are utilised in order to record the noise from the propulsion system of a vehicle in the semi-anechoic chamber [42]. Tyre/road noise, which is measured with a noise isolated vehicle, can then be added to the propulsion noise for the pass-by noise estimation [42]. The high accuracy of the indoor test facility is confirmed by tests in which the propulsion noise is considered only and, thus, slick tyres are applied on the vehicle. The comparison of indoor simulated pass-by noise and real pass-by noise against test track position in second gear shows an agreement within $1 \mathrm{~dB}(\mathrm{~A})$ for the overall pass-by noise level. However, the sound pressure levels of the one third octave spectra of the indoor simulation show higher variation, which is attributed to different absorption characteristics of the ground [42].

The indoor simulation of pass-by noise also supports the identification of the interaction of low frequency coherent noise sources. The engine, the intake and the exhaust systems belong to the group of coherent noise sources, since their noise emission mainly originates from the periodic pressure pulses of the intake and exhaust valves [13]. The noise of the intake and exhaust orifices is dominated by strong correlating engine order noise [13]. This results in a complicated directivity pattern [44]. For the correct calculation of the overall sound pressure level of a number of coherent noise sources, the phase information between the sound pressure signals from each noise source have to be considered. In this frequency range, the acoustic wavelength is of the same order as the vehicle length and approximately half the distance between the vehicle and the pass-by noise microphone. It is shown in Refs. $[13,44]$, that a distinctive interference pattern can be identified in the radiated sound field. Thus, the phase relationship between the signals has a significant influence on the location of the maximum and minimum sound pressure amplitudes. It is mentioned in Ref. [13] that the influence of constructive or destructive interference is less in practical situations due to the presence of many excitation frequencies and the contribution of uncorrelated noise signals. 
An example of the interference effects from low frequency coherent noise sources on the measured pass-by noise level in the ISO 362 test is reported in Refs. [20,45]. For the $100 \mathrm{~Hz}$ $1 / 3$ octave band, where the second engine order is expected to have a significant influence, two distinct peaks occur in the recorded sound pressure level against distance. The first peak occurs when the front of vehicle passes the microphone line. The second peak, which is higher in amplitude, occurs when the vehicle is far into the second half of the test track. Thus, it might be assumed that the first peak originates from the front of the vehicle whilst the second peak is related to the rear of the vehicle. However, near-field sound pressure measurements carried out indoors with a microphone array in a plane close to the vehicle result in the identification of the intake system as the noise source with the highest source strength. Thus, in this particular case the measured pass-by noise level in the far-field does not reflect the relative noise source strengths in the near-field of the vehicle. An illustration of such interference effects can also be seen in the $125 \mathrm{~Hz} 1 / 3$ octave band of Fig. 5 [11].

The indoor simulated pass-by noise test with microphone arrays does not replace the homologation process of the ISO 362, but it supports the development process from component to vehicle level [42]. It is a beneficial feature that environmental restrictions due to rain, wind speed, ambient temperature and pressure do not exist under indoor test conditions. The ground is ideally covered with a material meeting the requirements regarding texture and reflection characteristics according to ISO 10844 so as to increase the comparability with the ISO 362 test [40]. Variations caused by the human driver can be eliminated by automatic control of the accelerator pedal. Free-field conditions between the vehicle and the microphones are confirmed to be within $\pm 2.5 \mathrm{~dB}(\mathrm{~A})$ down to the lower cut-off frequency of about $50 \mathrm{~Hz}$ [40,42]. In Ref. [46], free-field conditions are verified to within $\pm 1 \mathrm{~dB}(\mathrm{~A})$ for one third octave band frequencies greater than $100 \mathrm{~Hz}$. Since ideal free-field conditions do not exist indoors, deviations from the ideal may impair the experimental results. The background noise of the chassis dynamometer must not contribute to the overall radiated noise. In Ref. [42], for an equivalent vehicle speed of 50 k.p.h., the measured background noise is less than $40 \mathrm{~dB}(\mathrm{~A})$ at a height of $1 \mathrm{~m}$ above the dynamometer. The wind noise created by a moving vehicle in air is not replicated, since its contribution to pass-by noise is assumed to be negligible in the speed range of the pass-by noise test.

Discrepancies between indoor simulated and real pass-by noise test remain, irrespective of the layout and characteristics of the indoor test facility, the number of microphones used and the algorithm applied to compose the overall signal. However, vehicles equipped with different components can be tested under the same conditions and their results compared. Vehicle noise sources can be shielded more easily due to the stationary position of the vehicle, thus, providing information about noise source contributions to the overall pass-by noise [40]. Other noise source identification techniques can be applied such as acoustic near-field holography or beamforming [41]. Beneficially, trained measurement personnel can walk around the vehicle during testing in order to conduct a subjective evaluation of the passby noise characteristics.

\subsection{Prediction of pass-by noise by experimental source strength quantification and airborne transfer functions}


The pass-by noise test arrangement can be described simplistically as a source-transferreceiver model [47]. This leads generally to two analysis steps: (1) the strength of each major noise source (engine, intake system, exhaust system, tyre/road system) has to be quantified acoustically; and (2) the transfer paths have to be quantified, since they describe the properties of the medium and space between each noise source and the pass-by microphones at the standard locations for each stage of the test. The acoustic characteristics of the sources as well as the properties of the relevant transfer paths change constantly during the test, which has to be considered in the prediction model. The combination of the source strengths and transfer paths results in a quantity, which is assumed to be the equivalent of the sound pressure at the ISO 362 microphone locations. This result can also be compared to pass-by noise target values or measured pass-by noise data of the preceding vehicle model or competitor models. The prediction model reveals the contributions of the dominant noise sources and critical transfer paths allowing for the implementation of countermeasures in the vehicle development stage.

Due to the instantaneous nature of the pass-by noise test, the operational condition of the vehicle and the distance to the microphone varies continuously. The operational source strengths can be determined with the noise source installed on a laboratory test rig or 'in-situ' on the vehicle. The transfer functions may be approximated by utilising a vehicle body without the major noise sources being active. The experimental quantification process can be conducted on an ISO 362 test track or in a vehicle semi-anechoic chamber with a chassis dynamometer $[14,48]$. The experimental quantification of acoustic source strengths and transfer paths as well as the prediction of pass-by noise is described in detail in the following sections.

\subsubsection{Quantification of noise source strengths}

In the pass-by noise test, airborne sound is transmitted from the vehicle noise sources to the two pass-by microphones. The radiating surfaces and open apertures on the vehicle are considered as sound sources [47]. The quantification of each airborne sound source enables an estimation to be made of the overall noise source strength.

In general, the sound radiation of an omni-directional monopole source and the sound pressure at a point receiver is assumed to be applicable in this case [49]. Therefore, the modelling approach for the determination of the real source strength is the discretisation of the vibrating surfaces of the main vehicle noise sources with uncorrelated omni-directional monopole sound sources [47]. These point sources are assumed to radiate noise, while the surfaces are assumed to be rigid maintaining the geometry of the structure [47].Due to the high impedance of most of the real noise sources, this becomes an acceptable approach [47]. Volume velocity, which can be obtained through sound pressure measurements in the near-field of the point sources, is selected as a quantity to represent the source strength of the monopoles. Fundamental investigations on this approach are reported in Ref. [50]. The assumption is that the whole system can be represented by a linear system. It is also required to provide a sufficiently dense arrangement of monopole sources to be spaced by half of the wavelength of the highest frequency of interest occurring in the system [50]. The sound field is assumed to be synthesised accurately, if the number of point sources and their 
amplitude and phase are chosen correctly [47]. Due to practical reasons, a spacing of half a wavelength between point sources in order to cover the vibrating surfaces of the real noise sources is not always feasible [50]. Consequently, the complex real sound sources are discretised into larger areas or patches [47]. Therefore, it is assumed that the amplitude of the point source volume velocity or the acoustic transfer function must be constant over each patch area [47]. A direct measurement of volume velocity is not possible. However, a measurement of the surface normal velocity is feasible, which is then multiplied by the patch area to obtain volume velocity. This approach is best suited to the lower frequency range with sound radiation from vibrating structural components [50]. The operational volume velocity of each patch can also be determined indirectly through sound pressure measurements. This is usually done where a measurement of the surface normal velocity is not feasible or at regions being difficult to access, for example, at nozzles, fans, tyres and exhaust components. The feasibility of the indirect determination of operational volume velocity makes it the preferred technique in the majority of the reviewed literature.

The quantification of the noise sources can be conducted with the noise sources assembled on the vehicle or with the noise sources disassembled from the vehicle and installed on test beds [12,52]. A free field environment is desirable. For in-vehicle testing, encapsulation of undesired noise sources may be applied in order to reduce crosstalk among the various vehicle noise sources [47]. The volume velocity of the source is assumed to be independent of the acoustic boundary conditions [52,53]. The vehicle noise sources are operated under speed and load conditions corresponding to the pass-by noise test. A small speed gradient can be used to improve readings under instantaneous conditions [3]. The engine speed is recorded in order to synchronise the operational sound pressure signals with the corresponding vehicle position on the test track [12]. The vehicle position can be estimated by the engine speed in conjunction with the transmission ratio, tyre dimensions and time taken.

Alternatively, the source strength quantification of the main vehicle noise sources can be conducted individually on test rigs independently of the vehicle. For the evaluation of a powertrain noise source, a good correlation between the test rig and the full vehicle measurements has been presented in Ref. [51]. In Ref. [54] the powertrain is operated in a semi-anechoic environment within the speed and load conditions of the pass-by noise test. The layout of the acoustic patches and the measurement procedure remains the same for individual noise source tests and the corresponding complete vehicle tests. However, only one microphone is used on each side of the engine-gearbox-assembly in cases, where it is attempted to isolate intake and exhaust system related noise [12]. Intake and exhaust orifice noise is measured on the vehicle driving on the track or on the chassis dynamometer in a semi-anechoic chamber with the other noise sources being masked [12]. Specially designed test rigs for intake or exhaust radiated noise present alternative options [54]. Intake orifice noise is recorded by a microphone, which is placed on an extension of the intake orifice axis without interfering with the intake air flow [54]. Exhaust orifice noise is measured by a microphone, which is positioned at a $45^{\circ}$ offset from the exhaust orifice axis to protect the microphone from heat and gas flow [3]. Alternatively, the exhaust orifice noise can be estimated by the application of 1D CFD simulation of the whole exhaust system as 
suggested in Ref. [12]. Tyre/road noise is measured on the vehicle through controlled braking to simulate the load influence on the system, since it is not possible to replicate the acceleration forces on the tyre/road system without measuring noise from the other major noise sources [12]. Therefore, microphones are attached to the vehicle and record sound pressure in the front, rear and on the side of the tyre.

The operational volume velocity of each vehicle noise source is obtained indirectly by a multiplication of the operational sound pressure spectra at the measurement positions in close proximity to the source patches and the transfer function spectra between these microphone positions and all remaining patches [47]. The convolution of the time history of sound pressure and impulse response function data is the equivalent approach in the time domain, which usually implies a higher expenditure of processing time. The transfer functions are determined individually in a direct [55] or reciprocal [47] approach. For areas difficult to access, the reciprocal determination of the transfer function is obtained by positioning a calibrated point sound source at the original microphone position and a microphone on the patch measuring the sound pressure response of a broad band excitation signal from the point sound source [47].The radiated volume velocity of the point sound source is calibrated prior to these measurements. For frequency domain data, the division of measured sound pressures and their corresponding broadband volume velocities results in the transfer function matrix. The inverse of the transfer function matrix is then multiplied, or convoluted, with the measured operational sound pressure, thus, estimating the operational volume velocity or source strength. The number of microphones should be at least twice the number of patches in order to apply a least squares optimisation of the inverted transfer function matrix, hence, avoiding ill-conditioning and negative values $[47,53,55]$. This technique is also applied in order to minimise errors from resonances in the engine compartment [56]. For all measurements, it is important to ensure that the microphones remain at their exact positions in order to avoid discrepancies in the sound pressure recordings [49]. The number of patches and microphones varies significantly. For example, equally sized areas of $0.1 \mathrm{~m}^{2}$ [47] and $0.04 \mathrm{~m}^{2}[51]$ up to an area the size of an engine side [12,55] are reported. However, subdivisions of the engine into the different sides of the engine block and oil pan, accessories and gearbox are also practiced [57]. For the other main noise sources, the intake orifice and air intake filter housing, exhaust mufflers and orifice, and leading and trailing edge of the drive wheels are considered as monopole sources [55,57]. In the case of a strong directional radiation characteristic of a surface or noise source, the utilisation of several microphones is recommended [56].

Several variations of this basic approach have been reported. In Ref. [57], an array of microphones is placed closely around the vehicle measuring the operational sound radiation from every noise source simultaneously whilst source isolation is omitted. This is in contrast to the method presented in Refs. $[47,53,55]$ in which microphones are positioned sequentially in close proximity to each noise source allowing for individual source strength quantification. In Ref. [57], a monopole source loudspeaker is placed at each microphone position in the array, and microphones measure the sound pressure at discrete locations near to the real noise sources, which represent the fictitious locations of the monopole sources. Thus, the transfer functions between microphone array and real noise sources are 
obtained, which are combined with the operational sound pressure resulting in the volume velocity source strength of each fictitious monopole source. The separation of the overall source strength into the contributions of each individual noise source component is achieved numerically. In Ref. [57], all numerical operations are carried out in the time-domain, since the rapid run-up recordings of the vehicle acceleration phase are believed to be captured better in the time domain [57]. A predicted pass-by noise signal allows for audible evaluation.

Alternatively, the determination of the transfer function matrix is omitted and instead the source strength is determined directly in Refs. [14,48]. Instead of using patches with equal areas and assuming constant surface velocity, operational source pressure is measured at defined positions in the near-field of each source. Then, the source volume velocity is obtained by inserting measured sound pressure values into the equation for a monopole point source, which provides a relation between sound pressure, distance and the volume velocity. All noise sources remain assembled on the vehicle. This experimental implementation reduces measurement time. The influence of this method on the accuracy of the source strength quantification and, hence, the predicted result is unknown. All noise sources are active in this case. The microphone positions have to be selected with care in order to keep errors regarding sound pressure measurement, source radiation characteristics and cross-talking at a minimum [48]. Cross-talk effects are due to the fact that the microphones not only record the radiated sound pressure from the noise source they are located closest to, but they also measure noise from the other sources. This effect increases if one or more of the other noise sources has a much greater sound radiation characteristic.

For indoor measurements, in a case where none of the vehicle noise sources is shielded during the determination of the operational noise source strengths, a correction function can be applied to improve the predicted pass-by noise signal $[14,48]$. If all noise sources are active and unshielded, microphones detect sound pressure not only from the closest noise source, but they also record cross-talk contributions from other noise sources. Furthermore, the complex radiation characteristics of the noise sources may not be captured thoroughly due to the limited number of microphones in the near-field of the sources. In order to improve the prediction result, correction functions are determined to account for the different radiation characteristics and cross talk. To determine the correction function, only a single group of noise sources is made active for that particular group. It is assumed that the radiation characteristic is not affected by the operating condition of a noise source. Hence, an operating condition similar to the pass-by noise test procedure is not necessary [14]. Therefore, in Ref. [14] the powertrain is driven in neutral gear at typical engine speeds, whilst the front and rear wheels are driven individually by the chassis dynamometer. A few microphones in the line array, which covers the whole distance of a vehicle pass-by, are selected as reference signals to measure the noise of the active group. Simultaneously, the microphones at the near-field positions of the non-active noise sources record noise from the active noise source which is, thus, a measure of the cross-talk from the active noise source. All near-field sound pressure measurements are combined with their corresponding transfer functions and summed in order to determine the far-field sound pressure at a given microphone in the line array. Deviations in the ratio of this synthesised signal to the measured sound pressure at the same position are related to cross talk and inaccuracies in 
the determination of the source radiation characteristic [14]. It is assumed that the deviations of this ratio are not affected by the location of the far-field microphone position or the operational conditions, thus, allowing them to be used as correction functions [48]. The correction function for the active group of noise sources is established as the ratio of the time-averaged synthesised to measured sound pressure for the selected microphones in the line array, which are then averaged over all reference positions resulting in a single correction function for each group of noise sources. The final results are spatial and timeaveraged correction functions for each noise source, which are applied to filter the pass-by noise contributions at each microphone in the line array. The proposed correction measure represents a simplistic approximation and partial coherence analysis is suggested as a more sophisticated technique [14]. However, the predicted sound pressure of this method produces differences of up to $5 \mathrm{~dB}(\mathrm{~A})$ for an approaching vehicle, in comparison to the ISO 362 test. A good agreement can be achieved for the maximum pass-by noise level, which occurs when the vehicle is about to leave the acceleration area. Although encapsulation measures on vehicle noise sources appear to be more feasible in indoor environments than outdoors, the prediction method is not conducted for encapsulated nonactive noise sources. A comparison is also made between the corrected prediction of passby noise based upon noise source contributions and an indoor simulated pass-by with microphone line arrays. Both signals correspond well indicating that their underlying techniques achieve results of a similar quality.

Another method relinquishes the determination of the operational volume velocities and uses sound pressure for source strength quantification instead [3,54]. Sound pressure on each engine side and at the intake and exhaust orifice is measured on test rigs under passby noise test conditions and used as operational source strength quantification [3]. In Ref. [56] it is reported that sound pressure is used to estimate the sound power of each radiating source, which can represent the source strength quantification alternatively.

A special case for tyre/road noise quantification is presented in Ref. [54]. It is assumed that radiated tyre/road noise is relatively unobstructed in its transfer path to the pass-by microphone. Thus, the noise of the motored vehicle is recorded at the standard microphone locations on the ISO 362 test track for several vehicle speed values, which cover the speed range of the vehicle in the pass-by noise test. The test is then repeated with the engine switched off and neutral gear selected in order to measure rolling tyre/road noise only. The rolling noise of different speeds are then associated with the corresponding positions of the vehicle on the test track for the real pass-by noise test. A correction to account for tyre/road noise due to vehicle acceleration is then applied on the recorded data in order to approximate the contribution of tyre/road noise to the overall pass-by noise level. This method is, thus, an approximation of the accelerated tyre/road noise test under full load by using rolling tyre/road noise. Its accuracy depends upon the correction frequency spectrum for the accelerated tyre/road noise and the number of speeds utilised in the rolling test. Furthermore, the decrease of vehicle speed in the rolling test needs to be considered.

The establishment of source strength databases can help to evaluate different types of noise sources in combination with different types of vehicle bodies. It is assumed in Ref. [12] that this may be valuable especially for the tyre/road system. If different engines or 
intake/exhaust systems are quantified separately on test rigs, their effect upon pass-by noise in combination with different vehicle body designs can also be estimated $[54,58]$.

\subsubsection{Quantification of transfer path characteristics}

After the determination of source strengths, the source-transfer-receiver model requires the identification of the acoustic transfer path characteristics between the location of the vehicle noise source and the pass-by receiver microphones. Transfer path characteristics include the effects of absorption and diffraction of the sound and also reflections from the track and adjacent surfaces as well as attenuation over distance [12,53,54]. Transfer paths can be determined either in the direct or reciprocal approach. The number and location of transfer paths are defined by the fictitious monopole sources modelling the real vehicle noise sources.

In the direct approach, a calibrated sound source with monopole characteristic is placed at the position of the real vehicle noise source and emits sound over a broadband frequency range. A microphone measures sound pressure at the receiver position. Due to the subdivision of the real noise sources into patches with fictitious monopole sources, the transfer functions between the centre of each patch and the pass-by microphone have to be determined. For practical implementation, artificial sound sources have to be placed within the original vibrating structure [49], which is hardly feasible. If they are positioned in the close vicinity or on the radiating structure, the whole system is basically falsified and the accuracy of the transfer functions is impaired [49] .However, suitable results are reported when using the direct approach in Ref. [55]. Alternatively, the original noise sources can be replaced with noise simulators of a similar shape and geometry. Each loudspeaker is activated individually to determine the whole set of transfer functions [54,58]. Noise simulators built for the engine, intake and exhaust orifice are reported in Refs. [54,58]. Using noise simulators enables the evaluation of different vehicle body designs, for example the effect of an engine compartment under-shield can be studied [54]. The transfer function is calculated by the division of the measured sound pressure spectrum at the pass-by microphone location by the radiated volume velocity.

A 'noise reduction' value can also serve as a descriptor of transfer path characteristics [54]. Sound pressure, radiated from the noise simulators, is measured the pass-by microphone location with and without the vehicle body. The difference between both sound pressure readings corresponds to the Noise Reduction value [54]. The greater the noise reduction value then the greater is the attenuation effect of the vehicle body. However, a system change occurs in this procedure, since the engine is removed from the engine bay for example, which may incur uncertainties or errors.

The idea of the reciprocal approach is to swap the positions of the source and receiver [50]. In practice, microphones are positioned at or as close as possible to the original noise source, while an artificial noise source, usually a loudspeaker with monopole characteristics, is placed at the original receiver microphone location. The system 'vehicle' is assumed to be barely changed by having the microphones in the vicinity of the sources. For pass-by noise modelling the reciprocal approach offers a feasible and quick solution by using microphones on the patches defined during the noise source strength determination procedure and 
powerful sound sources at the ISO 362 microphone locations. In the reciprocal approach only one sound source is required, while many noise sources are needed in the direct approach, or the measurement has to be repeated for every noise source patch with a single loudspeaker. Averaging of the transfer function is recommended [51,56]. A comparison of directly and indirectly determined transfer functions shows a difference of only $\pm 1 \mathrm{~dB}$ [49] confirming the applicability of the principle of reciprocity. The reciprocal approach appears to be the preferred method reported in the literature $[12,14,49,56,57]$.

The transfer path measurement procedure is repeated for several positions of the vehicle over the whole length of the test track, usually in increments of $1 \mathrm{~m}$. Transfer functions are interpolated three times between two adjacent microphone positions in Ref. [56]. The measurement procedure is carried out analogously in a semi-anechoic chamber, where the artificial sound source is moved through the microphone positions in the line array sequentially. If a smaller semi-anechoic chamber is used, corrections based on the inverse square law and the acoustic centre location can be applied [14]. Whether measurements are conducted indoors or outdoors, the asphalt surface should comply with the requirements of the ISO 10844 standard to ensure that comparable conditions regarding the actual pass-by noise test are applied [54]. In order to provide a realistic image of the transfer function behaviour in the pass-by noise test situation, it is recommended to equip the vehicle prototype with the insulation material which is planned to be used in the end product [51]. If the acoustic boundary conditions alter, for example, if acoustic insulation is added to the vehicle, then the transfer function has to be determined for the altered configuration [53].

Irrespective of the approach for the determination of the transfer functions, the artificial sound sources or loudspeakers have to be sufficiently powerful in order to overcome the effect of sound attenuation with distance from the ISO 362 microphone locations to the position of each noise source on the vehicle, and, thus, to record a signal with a sufficiently high signal-to-noise ratio, which can be utilised in the prediction technique. The devices are required to provide a spherical radiation characteristic over the frequency range of interest. In the direct approach, the size of the loudspeaker should be small enough, for example, to fit into the engine compartment [14,56]. Different signals are utilised in order to excite the surrounding medium over a large frequency range, for example, white noise [58] and swept sine [56]. The decisive criterion for the selection of the excitation signal is to achieve a high signal-to-noise ratio in conjunction with the available omni-directional sound source [56].

Transfer function measurements can be influenced by several parameters. The influence of temperature is investigated in a direct measurement procedure on a hot and a cold engine in Ref. [49]. A small shift in frequency, amplitude and phase for the case of higher temperature is reported. Another form of deviation can be caused by the air flow around the real noise sources. This can be either a result of the ambient air flowing around and into the vehicle or from the cooling process of the fan [49]. The positioning of microphones and sound sources should be precise in order to avoid significant deviations of up to $\pm 3 \mathrm{~dB}$ [49]. However, vehicle motion due to acceleration and the relatively large distance to the standardised microphone locations are reported to have a greater influence [49]. Nevertheless, the measurement errors may not be of practical significance, if they are within the positioning/calibration/measurement accuracy for one-third octave band data [49]. 
Omni-directional compact tube sound sources or volume velocity sources in rigid housings with a small orifice are commercially available and applicable for all measurements of the transfer function determination process. The devices are calibrated in anechoic conditions to obtain a relation between the radiated volume velocity and the loudspeaker input signal or the pressure inside the tube or housing $[49,52]$. Sound power is utilised instead of volume velocity in Ref. [56]. Ideally, the source strength is independent of the acoustic boundaries [53]. Thus, it does not alter if the source is utilised in the vehicle. Alternatively, different types of sound sources can be utilised to analyse different sections of the frequency range [48]. A frequency range of $20-4000 \mathrm{~Hz}$ is covered in the measurements reported in Refs. [14,48], while a frequency range from $200 \mathrm{~Hz}$ up to $8 \mathrm{kHz}$ have been covered with a mid-frequency volume velocity source in Ref. [55]. In Ref. [48], three different calibrated loudspeakers are used to provide monopole characteristics for different frequency ranges: a subwoofer (20$100 \mathrm{~Hz}$ ); a mid-frequency dodecahedron $(100-1200 \mathrm{~Hz})$; and a high-frequency dodecahedron $(1200-4500 \mathrm{~Hz})$. The measured signals in the three frequency ranges are superposed to obtain a single signal for the whole frequency range of interest. Experimental results of the mid-frequency dodecahedron show that the monopole characteristic is given within a deviation of $1 \mathrm{~dB}$ for its appointed frequency range [48]. Interchanging the position of the dodecahedron and the microphone in a reverberating environment in order to check reciprocity characteristics shows a small difference of up to $1 \mathrm{~dB}$, verifying its applicability for reciprocal measurements. However, if the positioning error is greater than $2 \mathrm{~cm}$, the deviations increase to more than $2 \mathrm{~dB}$ [48]. This emphasises the importance of precise positioning of all devices for an accurate measurement. Thus, the accuracy of the transfer function measurement depends upon the relative position of the loudspeaker to the microphone and the loudspeaker radiation characteristics. The experiments conducted in Ref. [48] lead to the conclusion that an error of about 1-2 dB may have to be tolerated in the transfer function measurement.

Transfer functions of the intake and exhaust orifice show the shielding effects of the vehicle body for the frequency range greater than $200 \mathrm{~Hz}[12,54]$. In the first half of the test track, the transfer function of the intake orifice shows higher amplitude values than the corresponding transfer functions of the exhaust orifice. This implies an amplification of the relevant frequency range of the intake orifice noise relative to the exhaust noise [12]. The transfer functions show the opposite tendency in the final half of the test track, which, thus, implies amplified exhaust orifice noise relative to intake orifice noise [12]. The transfer function spectra of different track positions of the engine, intake and exhaust system have similar amplitude values up to $100 \mathrm{~Hz}$. For higher frequencies, the difference between corresponding transfer functions increases by up to $10 \mathrm{~dB}$. Thus, indicating the different shielding characteristics of the vehicle body at the different measurement positions [59].

\subsubsection{Evaluation of the pass-by noise prediction}

After the identification of source strengths and transfer path characteristics for the sourcetransfer-receiver model, the final quantity, which is the predicted pass-by noise level, is determined. The overall pass-by noise signal is composed of the vehicle sound source contributions, which are a combination of source strengths and transfer path characteristics. 
The source contributions vary according to their condition, which generally depends upon the vehicle or engine speed, and the distance to the pass-by noise microphone. The source contributions are calculated at discrete positions over the whole test track length. The summation of all contributions produces the overall pass-by noise level at this particular position. If this step is repeated for all discrete positions, the result is the prediction of overall pass-by noise level against track position. The overall pass-by noise signal of adjacent discrete track positions can be interpolated in order to produce a continuous signal. If the experiments are carried out in a semi-anechoic chamber with microphone line arrays, the noise source contributions are determined for each microphone in the line arrays instead of a discrete track position. The overall pass-by noise signal is obtained by the superposition of each microphone signal.

The calculations can be carried out in the time or frequency domain. In the time domain, the operational source strengths are convolved with the corresponding impulse response functions, in order to obtain the noise source contributions [57]. In the frequency domain, the source contributions are calculated at a discrete track position by the product of the operational source strengths and the corresponding transfer functions [51]. The overall sound pressure level of the summed source contributions spectra yields the overall pass-by noise level at that particular position. The maximum frequency range of analysis depends mainly upon the artificial sound source utilised in the determination of the transfer functions.

The predicted results of the reviewed literature are presented either as overall pass-by noise level against track position or as one-third octave frequency spectra. The predicted overall pass-by noise signals correspond well with measured pass-by noise, regarding maximum levels, with deviations within $\pm 1 \mathrm{~dB}(A)[14,54,55]$. However, considering the duration of the pass-by noise signal against track position, deviations between 3-5 dB(A) can occur $[14,54,55]$. The predicted pass-by sound pressure level deviates by up to $\pm 3 \mathrm{~dB}$ in the one-third octave bands covering the frequency range of $200-8000 \mathrm{~Hz}$ [55]. It can be suspected that deviations in the narrow band frequency spectrum are higher. Although, deviations appear to be high in the frequency spectrum, the predicted overall pass-by noise level at the corresponding track position exhibits less deviation [3,55]. A comparison of the prediction methods in which the original noise sources remain on the vehicle and in which they are replaced by noise simulators produce similar outcomes, thus, demonstrating the suitability of either method for pass-by noise prediction techniques $[54,55,58]$. Since deviations occur between the measured and predicted pass-by noise levels, possible causes of the errors are likely to relate to inaccuracies in: (1) the characterisation of the noise source; (2) the estimation of the transfer paths; and (3) the modelling of the ISO 362 test.

The strengths of the vehicle noise sources can be determined virtually under operational conditions analogous to the conditions in the ISO 362 test. The radiation characteristics of the noise sources have to be captured comprehensively. The replacement of the real noise sources through a limited number of uncorrelated monopole sources may not be ideal, since the structure as a whole radiates sound. However, the reviewed prediction results indicate that it presents an acceptable approximation for pass-by noise. Furthermore, the number of microphones used in the measurement of operational source strength can be reduced 
significantly, to one microphone per engine side, for example, without materially compromising the quality of the predicted signal $[51,55]$.

The transfer path characteristics are only obtained at a limited number of discrete positions along the test track because of the otherwise vast accumulation of measurement data and the opportunity of interpolation. Suitable estimates of pass-by noise can be expected for the discrete positions at which the transfer functions are determined. For the interpolated regions, deviations can be expected from the actual pass-by noise signal. The loudspeakers used in transfer function determination should possess an omni-directional radiation characteristic and a sufficient sound power output to produce a high signal-to-noise ratio.

If pass-by noise measurements are carried out on a moving vehicle, deviations from runto-run can be caused by the change in the relative distance between transducer and measurement object, altered source impedance due to temperature variations, and air flow through and around the vehicle body [49]. Measurements with complete prototype vehicles on chassis dynamometers in semi-anechoic chambers are most frequently used, especially in more recent publications [14,51,55-57]. The ability of the indoor experiments to reproduce the outdoor test relies upon the reflection properties of the floor, the absorption capability of the walls, the correct source-to-microphone distance, and the replication of the tyre/road noise on the drum surface of the chassis dynamometer [53]. A factor in favour of an indoor implementation is that noise sources can be shielded more easily, thus, reducing their impact on the recording of the noise source of interest [47]. Furthermore, the indoor experiments can be controlled automatically without the need of a driver, which means that the point of acceleration is met accurately and that the distance between the vehicle centre line and any microphone does not vary. The radiation characteristics of the noise sources can be captured more thoroughly, since a large number of microphones can be positioned near to the noise sources of the stationary vehicle.

The transient nature of the pass-by noise test may cause measurement errors [58] and a low level of test repeatability, which is an obstacle in providing suitable data for comparison and verification purposes [60]. Averaging of data recorded under the non-stationary condition of a rapid vehicle run-up process is not advisable. Automatic vehicle control system may represent an improvement in this matter. The close monitoring of vehicle conditions such as engine and wheel speed, vehicle position, cooling fluid and fuel temperature and throttle position provides comparable data over several test runs [60]. Environmental or weather conditions affecting ambient temperature and pressure, air density, humidity, rain and wind speed may influence and even prevent outdoor measurements. Test series should be carried out within the same test facility in order to avoid deviations in the measurement results due to site-to-site variability. Measurement devices should meet the requirements of 'class one' instruments [5]. The road asphalt of the test track may cause a lack of repeatability and reproducibility. The recently revised standard, ISO 10844, provides guidelines regarding road surface texture and absorption as well as smoothness and evenness of the test track [61]. These factors can cause additional excitation and deformation in the tyre-suspension-system leading to varying noise radiation. The requirement regarding the acoustic property of the asphalt, for example, is an absorption coefficient of less than or equal to $8 \%$ determined at 
the one third octave frequencies within the range of $280-1800 \mathrm{~Hz}$ [61]. It is anticipated that variations in the pass-by noise levels will be reduced through adoption of the revised standard.

The reviewed methods on the source-path-receiver approach are suitable to predict changes in the pass-by noise levels for different vehicle configurations. However, so far, the exact pass-by noise level cannot be replicated. Nevertheless, a knowledge about source strength contributions and transfer path characteristics enables: (1) the analysis of source contributions and transfer paths to the overall pass-by noise [49]; (2) the establishment of a source ranking [51] and noise targets for the major noise sources [54]; (3) the evaluations of encapsulations, absorption properties or other additional countermeasures [49]; and (4) the analysis of road surface reflection on pass-by noise [49]. The technique offers more advanced opportunities than the windowing technique on a noise isolated vehicle due to insufficiencies in the insulation in the low-frequency range and possible small sound level differences between the quietest noise source and the completely noise isolated vehicle [59]. Further, in the application of the windowing technique, the noise sources cannot be separated from the transfer paths. The technique of experimental source strength quantification and airborne transfer functions is also applicable to the requirements of the revised ISO 362 standard, if operational source strength data of a constant-speed pass-by is available.

\subsection{Numerical methods for the prediction of pass-by noise}

This section gives an introduction to pass-by noise prediction by means of numerical methods. Such methods can analyse the pass-by noise characteristics of a vehicle in its early development stage, thus, reducing the experimental effort [62]. The neural networks technique and the Boundary Element Method (BEM) can be categorised within these approaches. The Fast Multipole Method (FMM) was recently applied to simulate very large BEM models without the typical sacrifices in calculation time and maximum analysable frequency.

\subsubsection{Neural networks approach}

A neural network consists of neurons, which are simple processing units, connected to each other to form a network [63]. An output value of a typical artificial neuron is derived from several input values which are multiplied by a weight, summed up, added with a bias and passed on to a transfer function. Advanced neural networks such as the 'multi-layer perceptron' consist of several inputs influencing different layers of neurons. A neural network can provide a predictive model from example data. Vehicle design parameters have a significant influence on pass-by noise, but an exact analytical calculation of noise at an early vehicle design stage is not possible. The application of neural networks for pass-by noise prediction offers a feasible alternative [64].

In Ref. [64] a ranked list of vehicle parameters affecting vehicle pass-by noise was established, which are practical to collect and applicable to any vehicle. These parameters serve as input values to the neural network model. A sufficiently high number of training examples, which is in the range of several thousands [64], are required to train the network. 
This data is obtained by the collection of test data from a large number of predecessor vehicles. Further data preparation, such as the definition of weighting factors, has to be conducted. A neural network for the estimation of vehicle performance in combination with the data for vehicle parameters and test conditions are the input to the neural networks model for pass-by noise prediction in Ref. [64]. The averaged error over all test cases of the predicted pass-by noise level in comparison to the actual pass-by noise level is just $\pm 1.4 \%$. However, the predicted results show a rather large distribution and deviations of 2-4 $\mathrm{dB}(\mathrm{A})$ for many data points. Deviations increase in the case of a new, quieter vehicle. The network has to be retrained constantly with the latest vehicle technology otherwise a possible source of error may occur due to technology leaps in the most recently developed vehicles. Another disadvantage may be the provision of the vast amount of test data from previous vehicle models, which may be difficult to collect.

\subsubsection{Boundary Element Method}

The Boundary Element Method (BEM) calculates the sound pressure level at a specified location in space from the excitation of a medium by a noise source. The source and the receiver locations are modelled by mesh structures. Sufficient computer resources are important prerequisites for the satisfactory performance of a BEM simulation. Mostly, a tradeoff between model accuracy and available computer facilities has to be made $[62,65]$. For the prediction of vehicle pass-by noise, a highly complex model would have been to be set up which automatically leads to a requirement for high performance computing.

In general, six to ten elements are required to accurately represent an acoustical wavelength. This has an impact on the maximum analysable frequency range and subsequent computation time. If a whole vehicle is to be modelled for the analysis of exterior noise propagation, the number of elements is enormous and, hence, the calculation time increases heavily. Hence, this method is not applicable in practice for higher frequencies than $500 \mathrm{~Hz}$ [62]. Another aspect of concern is the frequency resolution, which increases the computation time the higher it is. It may be possible to estimate the transfer function by a small number of frequency data points, however, the quality of the transfer function may be compromised [62].

In Ref. [65] a BEM model of the four major noise sources (engine, intake manifold, exhaust tailpipe, tyres) plus vehicle body is established to estimate pass-by noise at 23 specific frequencies within the range of $19.95-3162.2 \mathrm{~Hz}$. Each noise source is modelled via a generic source, which represents an approximated geometry of the real source dimensions. Thus, the build-up of the model is simplified, and the computation time is reduced. The radiated acoustic field of each generic source is reconstructed via sound pressure measurements in the vicinity of the real noise source during a pass-by noise test. Thus, the excitation velocities on the surface elements of the generic source are derived, and the calculated sound pressure values can be assessed against the measured values.

Transmission and reflection effects caused by the vehicle body and the ground are incorporated in the BEM model. The pass-by noise evaluation points are included as a line of field points along both sides of the vehicle model at $7.5 \mathrm{~m}$ distance and $1.2 \mathrm{~m}$ height. Since the mesh structure consists of openings and multiple connections, the Indirect BEM is 
applied to obtain the transfer functions between the generic sources and the evaluation points. The combination of the surface velocities on the generic sources and the corresponding transfer functions result in a pass-by noise prediction. All noise sources are regarded as incoherent. The maximum overall A-weighted sound pressure level of a pass-by in 3rd gear is calculated and compared with the measured value. The deviation is only $1.1 \mathrm{~dB}(\mathrm{~A})$, with the computed level the slightly higher value [65]. However, a comparison of the pass-by noise level against track position is not given in Ref. [65]. Further, this technique depends on sound pressure measurements, otherwise the reconstruction of the acoustic field of the noise sources is not feasible.

The sound radiation of an engine-gearbox structure is simulated using BEM in Ref. [66]. A commercial vehicle Diesel engine with a manual transmission is the foundation of the simulation model, which is limited to noise from stationary operational conditions. Excitation through combustion forces is considered as well as mechanical excitation through play and dynamic mass inertias. This leads to a calculation of the reaction forces at the bearing positions of the engine-gearbox-structure. The structural transfer characteristics are simulated with a finite element model of the engine-gearbox-unit. As a result, the normal surface velocity distribution is obtained. Boundary element models are generated from the existing finite element models in order to simulate sound radiation. The sound pressure distribution in the far-field at discrete frequencies is calculated from the normal surface velocities. The simulation is carried out only for a few components of the engine-gearbox structure due to the intensive computation time. Since not all excitation mechanisms are considered in the simulations, it is difficult to achieve an accurate quantitative value of the sound pressure distribution. However, the qualitative evaluation represents a good idea of the directivity characteristics of the analysed components.

The Fast Multipole Boundary Element Method (FMBEM) can overcome the trade-off of the limited maximum frequency versus excessive computation time of the traditional BEM [62]. In the application of FMBEM, the structural/acoustic model is subdivided into several clusters. The cluster of a noise source contains elements in the near-field of that particular source. In order to obtain the acoustic response in the far-field target cluster, all points of a source cluster are collected together to represent a single multipole, from which noise is radiated to the target cluster and, thus, sound pressure is evaluated on the target points. Clusters, which are far away from the source cluster, can be combined into groups of clusters leading to a hierarchical arrangement and, thus, to a significant reduction in computation time. Therefore, the FMBEM can be applied to BEM problems involving millions of degrees of freedom and reduce them to the order of tens of thousands. It also increases the maximum frequency of analysis up to $2 \mathrm{kHz}$.

In Ref. [62] the FMBEM is applied to calculate the transfer functions between the source and receiver locations of a pass-by noise test configuration which utilises two receiver locations: in front; and on the side of the vehicle at $4.3 \mathrm{~m}$ distance to the vehicle centre line. An experimental setup of a vehicle in a semi-anechoic chamber provides comparison data. The major noise sources are modelled as point sources. Their source strengths are quantified by volume velocity, which can be obtained by measurements or simulations. Reflections from the ground are considered in the model. An average deviation of up to $4 \mathrm{~dB}$ 
occurs for the comparison of simulated and measured pass-by noise levels from all transfer paths. These discrepancies are considered to be mainly related to the poor quality of the modelling of the noise sources inside the engine compartment.

\section{Summary}

Vehicle noise source characteristics in the ISO 362 pass-by noise test are analysed from an extensive literature review and presented in consolidated form in this paper. Four major noise sources contribute significantly to the pass-by noise level: engine, intake system, exhaust system and the tyre/road system. The maximum pass-by noise level usually occurs when the vehicle has just passed the microphone positions. This is because of the combination of the noise source strengths and radiation characteristics as well as the relatively short distance to the response microphones. The engine, exhaust orifice and the interaction of the tyre and road surface contribute most significantly in this particular position on the track, whilst the intake orifice noise may be slightly shielded by the vehicle body. The highest engine speed, which is achieved at the end of the acceleration period, generally incorporates the highest noise source strengths. However, the pass-by noise level is reduced due to an even greater decrease because of distance attenuation. The contribution of the exhaust orifice begins to increase when the vehicle passes the microphone positions as the shielding effect of the vehicle body is no longer present. Conversely, the contribution of the intake system decreases in this situation. The relative rankings and source contributions will, of course, vary due to vehicle type and configuration.

The causes of vehicle noise generation and the subsequent noise source radiation characteristics are, in general, very complex. The main engine noise radiation occurs behind the front axle through the gap between the lower side of the vehicle body and the ground and in the direction towards the pass-by noise microphones. As a result of the reciprocating engine process, the significant frequency characteristics are the engine orders. Pressure pulsations at the intake and exhaust valves of the engine are the main excitation source for the intake and the exhaust system noise. Gas flow in their piping systems is the source for flow noise, which occurs as a broadband noise in the mid-frequency range. At the exhaust orifice, the mixing of hot exhaust gas and still ambient air is the cause of jet noise. Tyre/road interaction noise is caused by the impact, adhesion and air-displacement mechanisms between the tyre and the road. The horn effect can provide a significant amplification of tyre/road noise, thus, increasing its potential contribution to pass-by noise. Dominant frequencies are around $1000 \mathrm{~Hz}$. The main sources of noise are located close to the contact patch at the leading and trailing edges of the tyre.

Methods to estimate pass-by noise generally rely upon experimental methods to determine the noise source contributions at discrete track positions and then combine these with the transfer path characteristics from the source location to the pass-by noise microphone position. Good prediction results are reported for the maximum pass-by noise level. If pass-by noise is analysed over the whole track length or in the frequency domain the accuracy varies, mainly between 1-3 $\mathrm{dB}(\mathrm{A})$. In an alternative approach, linear arrays of microphones on both sides of a vehicle, which is mounted on a chassis dynamometer in a semi-anechoic chamber, were utilised in order to reciprocally simulate the pass-by noise test. 
For both techniques, the availability of physical prototypes has to be assumed. In contrast, numerical prediction methods do not require a prototype and show the potential to determine the pass-by noise level of a virtual vehicle at an early stage in the design process. However, reported deviations of up to $4 \mathrm{~dB}$ indicate that they can only provide initial estimates of the final pass-by noise level.

\section{References}

[1] Fritschi L, Brown AL, Kim R, Schwela D, Kephalopoulos S. Burden of disease from environmental noise - Quantification of healthy life years lost in Europe. Copenhagen: World Health Organization Regional Office for Europe; 2011.

[2] Commission Directive 2007/34/EC of 14 June 2007 amending, for the purposes of its adaption to technical progress, Council Directive 70/157/EEC concerning the permissible sound level and the exhaust system of motor vehicles. 2007.

[3] Phillips AV, Orchard M. Drive-by noise prediction by vehicle system analysis. SAE Technical Paper Series 2001-01-1562; 2001.

[4] BS ISO 362. Acoustics - Measurement of noise emitted by accelerating road vehicles Engineering method. London: British Standards Institution; 1998.

[5] BS ISO 362. Measurement of noise emitted by accelerating road vehicles - Engineering method - Part 1: M and N categories. London: British Standards Institution; 2007.

[6] de Roo F, Dittrich MG, van Beek PJG, Bosschaart C, Derksen GB, de Kievit M. VENOLIVA - Vehicle Noise Limit Values - Comparison of two noise emission test methods - Final Report. Delft: TNO Science and Industry; 2011.

[7] Proposal for a regulation of the European Parliament and of the Council on the sound level of motor vehicles (2011/0409 (COD)). Brussels: European Commission, 09.12. 2011.

[8] Sandberg U, Ejsmont JA. Tyre/road noise reference book. Kisa (Sweden): Informex; 2002.

[9] Biermann J-W. Geräuschverhalten von Kraftfahrzeugen (Noise characteristics of vehicles) - Lecture notes. Aachen: Institute for vehicles at RWTH Aachen University; 2004.

[10] Taylor N. Pass-by noise - A brief overview. Presentation held at Loughborough University; 2007.

[11] VDI-Richtlinien 2563. Geräuschanteile von Straßenfahrzeugen - Meßtechnische Erfassung und Bewertung (Guideline of the Association of German Engineers (VDI): Noise components of vehicles; measurement and assessment). Düsseldorf: Verein Deutscher Ingenieure; 1990.

[12] Alt N, Wolff K, Eisele G, Pichot F. Fahrzeugaussengeräuschsimulation (Vehicle exterior noise simulation). Automobiltechnische Zeitschrift 2006;108:832-36.

[13] Zeller P. Handbuch Fahrzeugakustik (Handbook Vehicle Acoustic). Wiesbaden: Vieweg + Teubner; 2009.

[14] Genuit K, Guidati S, Sottek R. Progresses in pass-by simulation techniques. SAE Technical Paper Series 2005-01-2262; 2005. 
[15] Arndt R, Fliesser W, Rein D, Fankhauser C. Analysis of pass-by noise using Nearfield Acoustic Holography. In: Proceedings of the joint congress CFA/DAGA '04; 2004. p. 1920.

[16] Biermann J-W, Beckmann T, Wech L, Meier R. Analyse des Reifenabrollgeräuschs mit einem Messfahrzeug (Analysis of rolling noise with a measurement vehicle). Automobiltechnische Zeitschrift 2004;106:2-7.

[17] Lee JW, Min KJ. A reduction of vehicle pass-by noise by experimental approach. In: Proceedings InterNoise; 1996.

[18] Balcombe DR, Crowther PJ. Practical development problems in achieving $74 \mathrm{~dB}(\mathrm{~A})$ for cars. In: Noise and the automobile: Selected papers from Autotech'93 which took place at the National Exhibition Centre, Birmingham, UK. London: Mechanical Engineering Publications; 1993. p. 109-15.

[19] Harrison M. Vehicle Refinement - Controlling Noise and Vibration in Road Vehicles. Oxford: Elsevier Butterworth-Heinemann; 2004.

[20] Gade S, Rasmussen P, Taylor N. Passby measurement vs. STSF passby simulations. In: Proceedings InterNoise; 1996. p. 3087-92.

[21] Bosch - Kraftfahrteschnisches Taschenbuch (Automotive Handbook). 25th ed. Wiesbaden: Vieweg+Teubner; 2004.

[22] Pischinger S. Engine Acoustics (Lecture notes). Aachen : Institute of combustion engines at RWTH Aachen University; 2006.

[23] Park S-H, Kim Y-H. Visualization of pass-by noise by means of moving frame acoustic holography. J Acoust Soc Am 2001;110:2326-39.

[24] Ginn KB, Newton G. Contribution analysis in pass-by testing using moving source beamforming. SAE Technical Paper Series 2011-01-1669; 2011.

[25] Wang $X$. Vehicle noise and vibration refinement. Cambridge: Woodhead Publishing; 2010.

[26] Pischinger S, Stoffels H, Steffens C, Aymanns R, Stohr R, Atzler M. Akustische Auslegung von Abgasturboladern (Acoustic design of turbochargers). Motortechnische Zeitschrift 2008;3:238-45.

[27] Davies POAL, Harrison MF. Predictive acoustic modelling applied to the control of intake/exhaust noise of internal combustion engines. J Sound Vibr 1997;202:249-74.

[28] Davies P, Holland K. I.C. engine intake and exhaust noise assessment. J Sound Vibr 1999;223:425-44.

[29] Hueser M, Govindswamy K, Wolff K, Stienen R. Sound quality and engine performance optimization development utilizing air-to-air simulation and interior noise synthesis. SAE Technical Paper Series 2003-01-1652; 2003.

[30] GT-Power User's Manual - Version 6.2. Westmont (II, USA): Gamma Technologies, Inc.; 2006.

[31] Alfredson R, Davies P. The radiation of sound from an engine exhaust. J Sound Vibr 1970;13:389-408.

[32] Munjal ML. Acoustics of ducts and mufflers (with application to exhaust and ventilation design). New York: John Wiley \& Sons; 1987. 
[33] Abe T, Yoshimori K, Azuma A. Exhaust noise abatement with porous sintered metal silencer. SAE Technical Paper Series 850326; 1985.

[34] Endo M, Futagami Y, Iwamoto J. Relation between the flow pattern downstream of duct and the noise. JSAE Review 2000;21:125-32.

[35] Fujita K, Abe T, Hori Y. Simulation of acceleration pass-by noise considering the acoustic radiation characteristics of a vehicle body. Int J Veh Des 1987;8:514-25.

[36] Kropp W, Bécot F-X, Barrelet S. On the sound radiation from tyres. Acta Acustica united with Acustica 2000;86:769-79.

[37] Mori Y, Fukushima A, Uesaka K, Ohnishi H. Noise directivity of vehicles on actual road. In: Proceedings Inter-Noise; 1999. p. 1-4.

[38] Steven H. Pkw-Reifen/Fahrbahngerausche bei unterschiedlichen Fahrbedingungen (Tyre/road noise of passenger vehicles in different driving conditions). Frankfurt/Main: Forschungsvereinigung Automobiltechnik e.V.; 2000.

[39] Iwao K, Yamazaki I. A study on the mechanism of tire/road noise. JSAE Review 1996;17:139-44.

[40] Dreyer W, Hoppe P, Friederich P, Fuchs H. Das neue Volkswagen-Akustikzentrum in Wolfsburg - Teil 1: Prüfstände (The new centre of acoustics of Volkswagen in Wolfsburg - Part 1: Test Facilities). Automobiltechnische Zeitschrift 2003;105:250-60.

[41] Ryu Y, Lange S. The design and validation of simulated indoor passby noise measurement system. SAE Paper 2007-26-033; 2007.

[42] Finsterhölzl H, Caldiero V, Hobelsberger J, Baumann W, Daiber F. Neuer Außengeräuschprüfstand im Entwicklungsprozess bei BMW (New exterior noise test facility in the development process at BMW). Automobiltechnische Zeitschrift 2006;108:256-67.

[43] Sandberg U. Possibilities to replace outdoor coast-by tyre/road noise measurements with laboratory drum measurements. Project "Silence", European Commission DG Research, Sixth Framework Programme, Priority 6, Contract No. 516288; 2006.

[44] Rasmussen P. Pass-by Noise Measurements. Brüel\&Kjær Technical Review, No. 1; 1995.

[45] Taylor N, Rasmussen P. Exterior noise measurement on a Rover 220 GSi. Brüel\&Kjær Application Note, BO0430; 1995.

[46] Fuchs H, Zha X, Babuke G, Friederich P. Das neue Volkswagen-Akustikzentrum in Wolfsburg - Teil 2: Reflexionsarme Raumauskleidungen (The new centre of acoustics of Volkswagen in Wolfsburg - Part 2: Low Reflection Room Linings). Automobiltechnische Zeitschrift 2003;105:372-82.

[47] van der Linden PJG, Defay H, Le Martret JP. Truck pass-by noise, detailed sources contribution identification during ISO R 362 pass-by. In: Proceedings on the international seminar on modal analysis $21 ; 1996$. p. 47-54.

[48] Guidati S, Sottek R, Genuit K. Simulated pass-by in small rooms using Noise Synthesis Technology. In: Proceedings of the joint congress CFA/DAGA '04; 2004. p. 21-22.

[49] van der Linden PJG, Mantovani $M$. The validity of reciprocal acoustic transfer function measurements on trucks for pass-by noise. In: Proceedings InterNoise; 1996. p. 2661-6. 
[50] Mason J M, Fahy FJ. Application of a reciprocity technique for the determination of the contributions of various regions of a vibrating body to the sound pressure at a receiver point. In: Proceedings of the Institute of Acoustics; 1990. Vol. 12(1):469-76.

[51] Fleszar AR, van der Linden PJG, Johnson JR, Grimmer MJ. Combining vehicle and testbed diagnosis information to guide vehicle development for pass-by noise. SAE Technical Paper Series 2001-01-1565; 2001.

[52] van der Linden PJG. PIANO - Synthesis report for publication: New pass-by noise optimization methods for quiet and economic heavy road vehicles. Project funded by the European Union under the BRITE EURAM Programme, Project No. 5414 PIANO, Contract No. BRE2-CT'-92O210; 1996.

[53] van der Linden PJG, Goossens S, Jönnson O. Correction of indoor pass-by noise measurments to estimate ISOR 362 outdoor noise using acoustic transfer functions. In: Proceedings of the international seminar on modal analysis 21 ; 1996. p. 37-46.

[54] Phillips AV, Bruno A, Orchard M, Rhodes DM, Shiau N-M. A process for vehicle drive-by noise analysis. London: IMechE Conference Transactions - European Conference on Vehicle Noise and Vibration; 2000. p. 319-30.

[55] Janssens K, Aarnoutse P, Gajdatsy P, Britte L, Deblauwe F, van der Auweraer H. Timedomain source contribution analysis method for in-room pass-by noise. SAE International 2011-01-1609; 2011.

[56] Stücklschwaiger W. Experimental pass-by noise source analysis - Approach based on measured transfer functions. Project "Silence", European Commission DG Research, Sixth Framework Programme, Priority 6, Contract No. 516288; 2006.

[57] Ryu Y, Schuhmacher A, Hirayama M, Shirahashi Y. Contribution analysis of exterior noise with indoor pass-by measurement. SAE International 2011-26-0062; 2011.

[58] Demmerer S. Simulation von Schallfeldern am Kraftfahrzeug (Simulation of sound fields on a vehicle). PhD Thesis, Technical University Munich; 2002.

[59] Biermayer W, Brandl FK, Pflüger M. Analyse und Optimierung des Vorbeifahrtgeräusches von Fahrzeugen (Analysis and optimisation of vehicle pass-by noise). Automobiltechnische Zeitschrift 2004;106:426-32.

[60] van der Linden PJG, Otte DAC. Diagnosis of pass-by noise of road vehicles. In: Noise and the automobile: Selected papers from Autotech'93 which took place at the National Exhibition Centre, Birmingham, UK. London: Mechanical Engineering Publications; 1993. pp. 99-108.

[61] BS ISO 10844. Acoustics - Specification of test tracks for measuring noise emitted by road vehicles and their tyres. London: British Standards Institution; 2011.

[62] Huijssen J, Fiala P, Hallez R, Donders S, Desmet W. Numerical evaluation of sourcereceiver transfer functions with the Fast Multipole Boundary Element Method for predicting pass-by noise levels of automotive vehicles. J Sound Vibr 2012;331:2080-96.

[63] Fry J, Jennings $P$, Taylor N, Jackson P. Vehicle drive-by noise prediction: A neural networks approach. SAE Technical Paper Series 1999-01-1740; 1999.

[64] Fry J, Jennings P. Using multi-layer perceptron to predict vehicle pass-by noise. Neural Computing \& Applications 2003;11:161-7. 
[65] Zhang Z, Vlahopoulos N, Allen T, Zhang KY. Development and validation of a computational process for pass-by noise simulation. Int J Veh Des 2004;34:12-34.

[66] Gold PW, Schelenz R, Fechler J, Hollenstein M, Pischinger S, Lahey H-P, Steffens C, Andres $O$. Akustische Untersuchungen im Gesamtsystem Verbrennungsmotor-Getriebe (Acoustic investigations of the system of combustion engine and gearbox).

Automobiltechnische Zeitschrift 1999;101:2-8.

\section{Copyright acknowledgements}

Figs. 12, 13, 21, 22, 23, and 24 are reprinted with permission from 'Park S-H, Kim Y-H. Journal of the Acoustical Society of America, vol. 110 pp. 2326-39 (2001)'. Copyright 2001, Acoustical Society of America.

Fig. 14 is reprinted from 'Zeller P. Handbuch Fahrzeugakustik (Handbook Vehicle Acoustic). Vieweg + Teubner Verlag; 2009'. With kind permission of Springer Science and Business Media. 


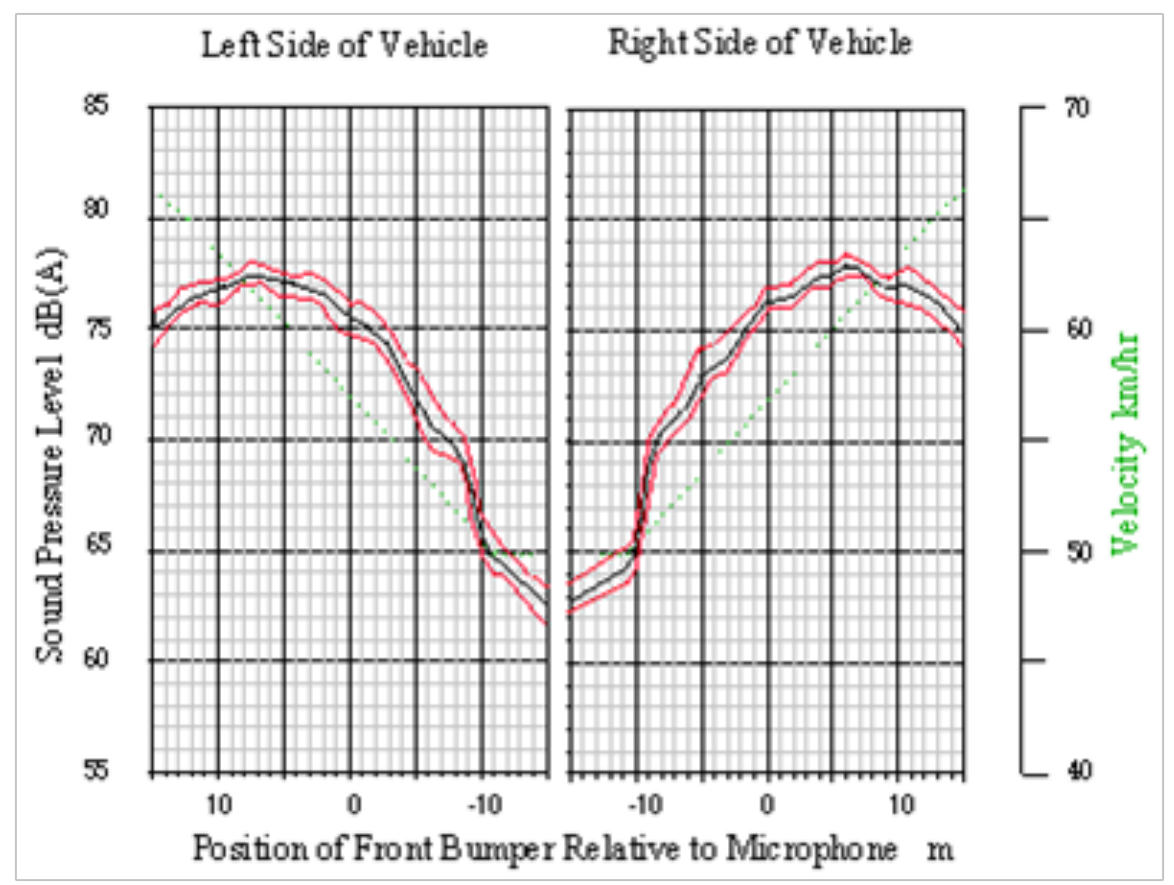

Fig. 1. Pass-by noise recording in 2nd gear according to ISO 362 [10]. 


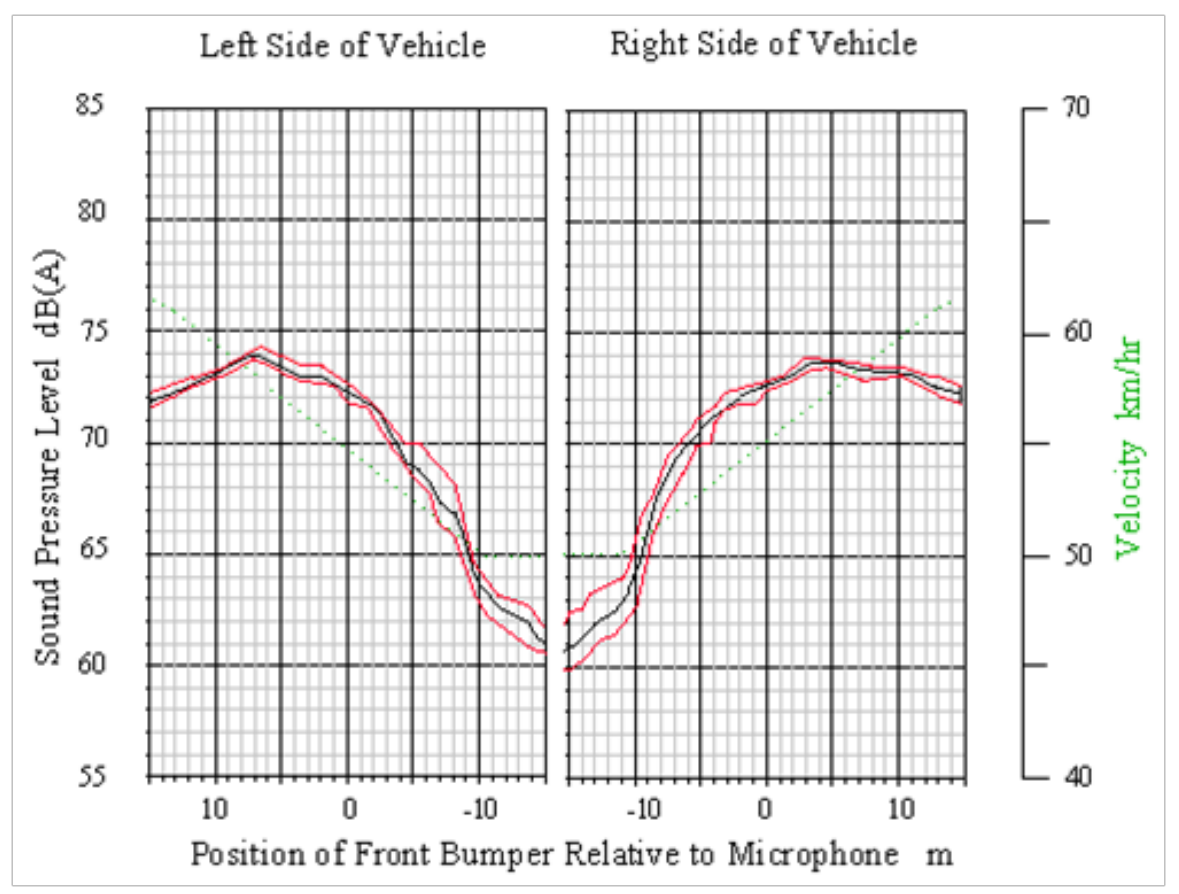

Fig. 2. Pass-by noise recording in 3rd gear according to ISO 362 [10]. 


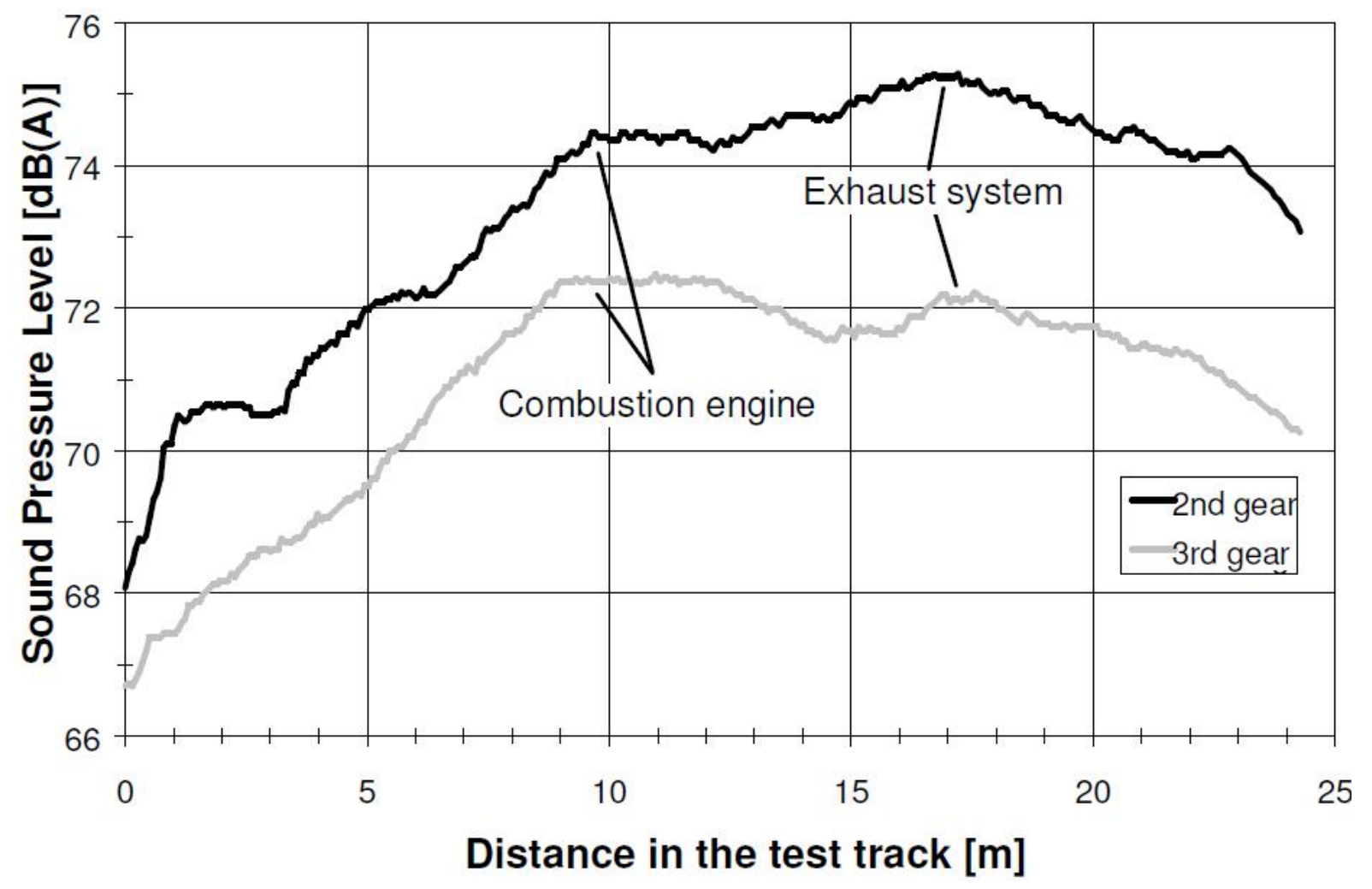

Fig. 3. Pass-by noise recording of the left-hand side microphone in $2 \mathrm{nd}$ and $3 \mathrm{rd}$ gear of a medium class vehicle according to ISO 362 [9] (reprinted from 'Biermann J-W.

Geräuschverhalten von Kraftfahrzeugen (Noise characteristics of vehicles) - Lecture notes.' With kind of permission of Prof Biermann). 


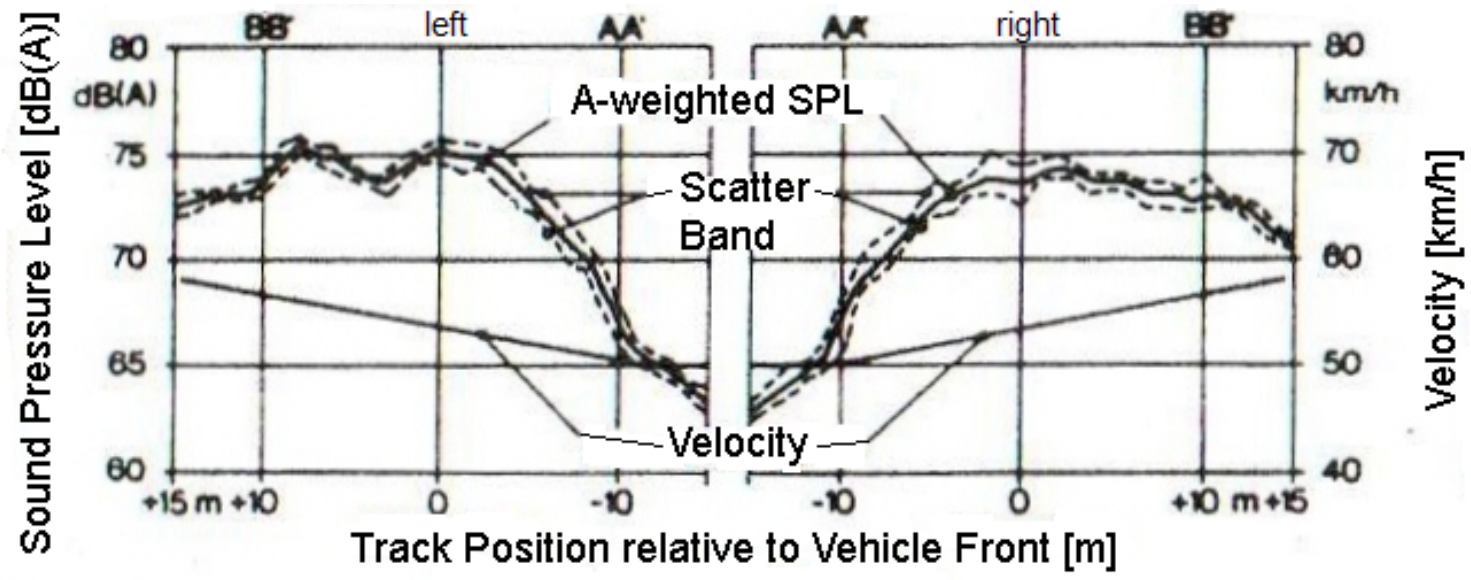

Fig. 4. A-weighted pass-by noise level of the left-hand (left) and right-hand (right) side of the vehicle [11] (reprinted from 'VDI-Richtlinien 2563. Geräuschanteile von Straßenfahrzeugen Meßtechnische Erfassung und Bewertung (Guideline of the Association of German Engineers (VDI): Noise components of vehicles; measurement and assessment). Düsseldorf: Verein Deutscher Ingenieure; 1990.' With kind permission of Verein Deutscher Ingenieure). 


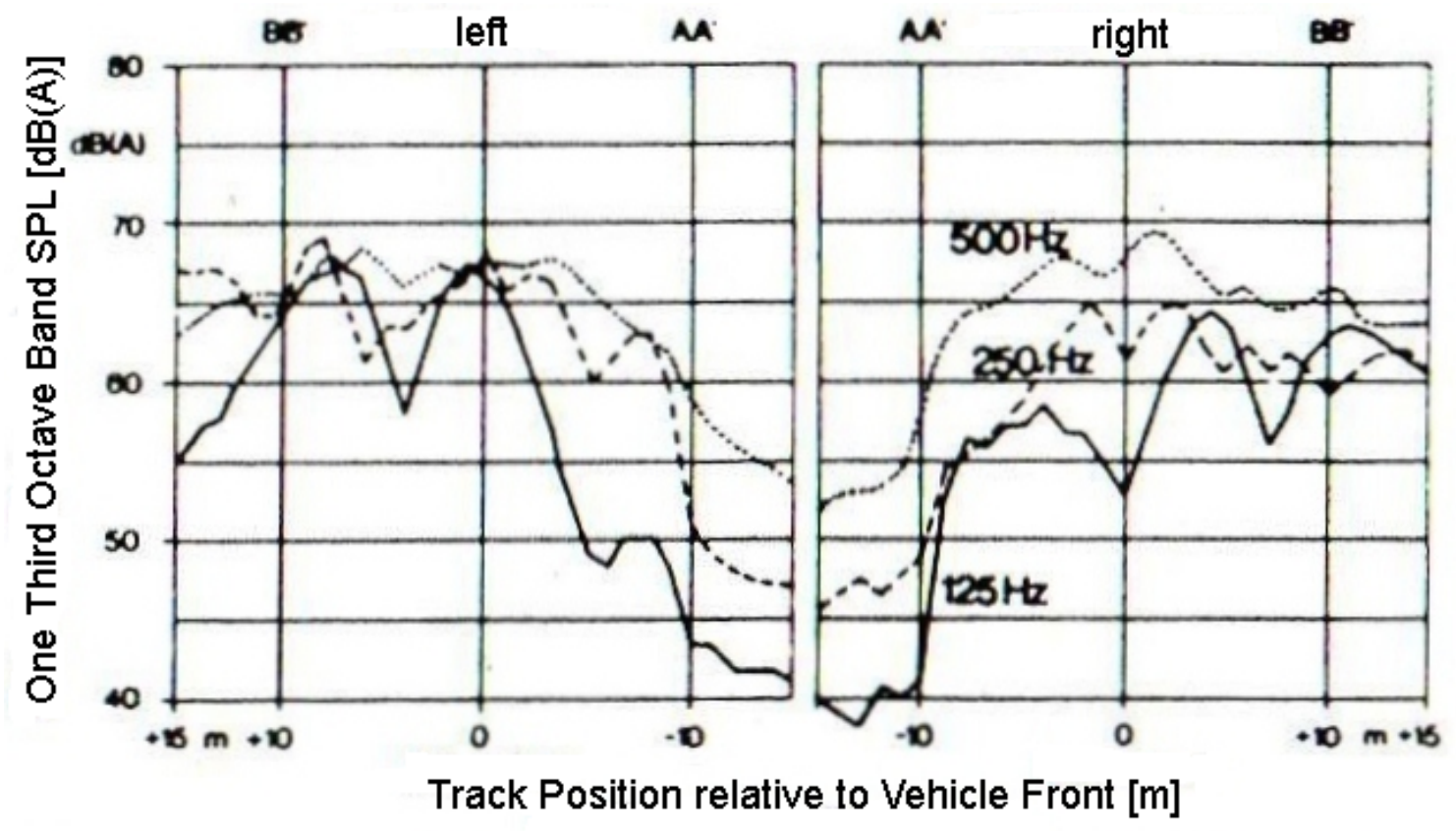

Fig. 5. A-weighted pass-by noise octave band levels from $125 \mathrm{~Hz}$ to $500 \mathrm{~Hz}$ [11] (reprinted from 'VDI-Richtlinien 2563. Geräuschanteile von Straßenfahrzeugen - Meßtechnische Erfassung und Bewertung (Guideline of the Association of German Engineers (VDI): Noise components of vehicles; measurement and assessment). Düsseldorf: Verein Deutscher Ingenieure; 1990.' With kind permission of Verein Deutscher Ingenieure). 


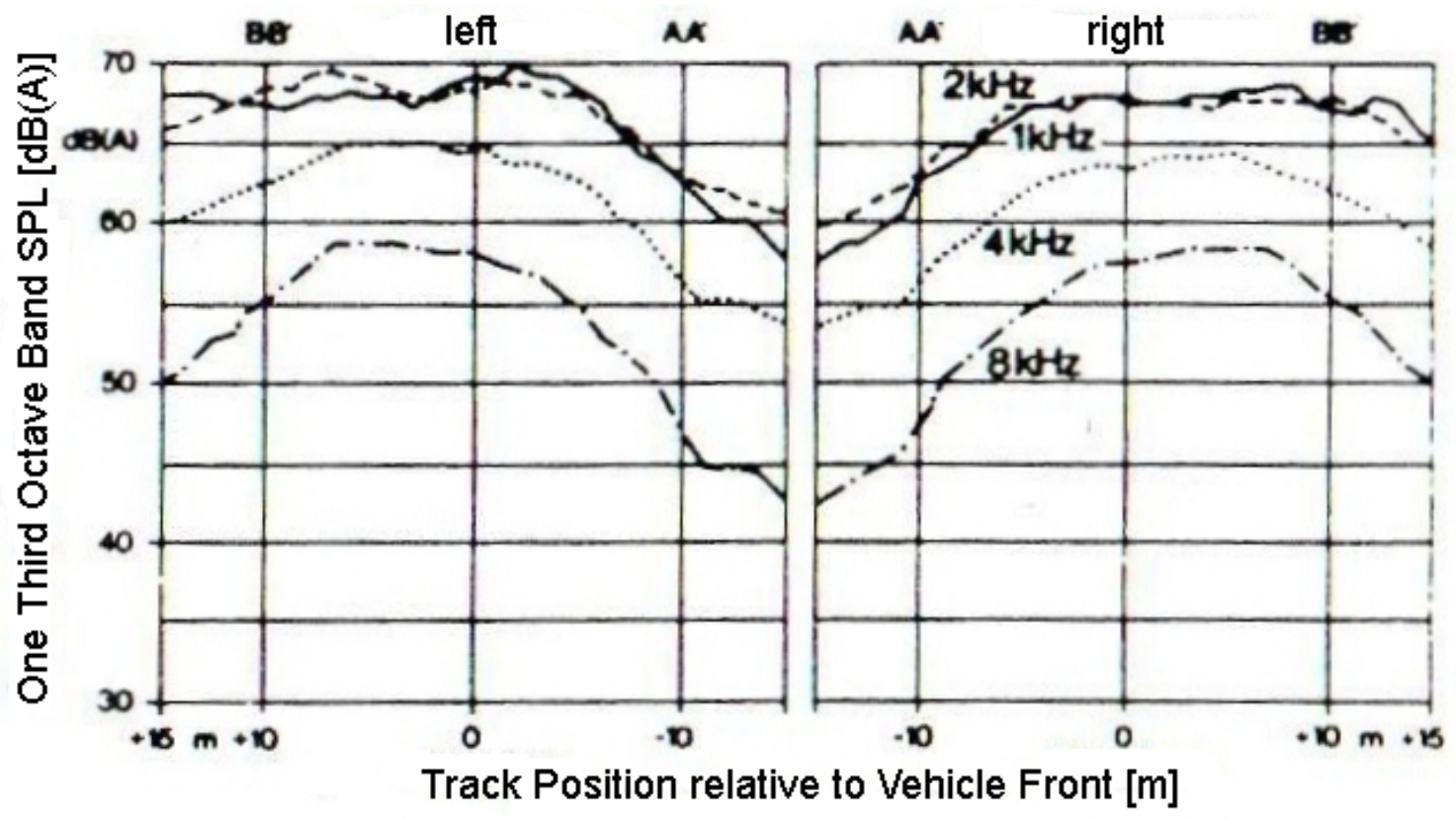

Fig. 6. A-weighted pass-by noise octave band levels from $1 \mathrm{kHz}$ to $8 \mathrm{kHz}$ [11] (reprinted from 'VDI-Richtlinien 2563. Geräuschanteile von Straßenfahrzeugen - Meßtechnische Erfassung und Bewertung (Guideline of the Association of German Engineers (VDI): Noise components of vehicles; measurement and assessment). Düsseldorf: Verein Deutscher Ingenieure; 1990.' With kind permission of Verein Deutscher Ingenieure). 

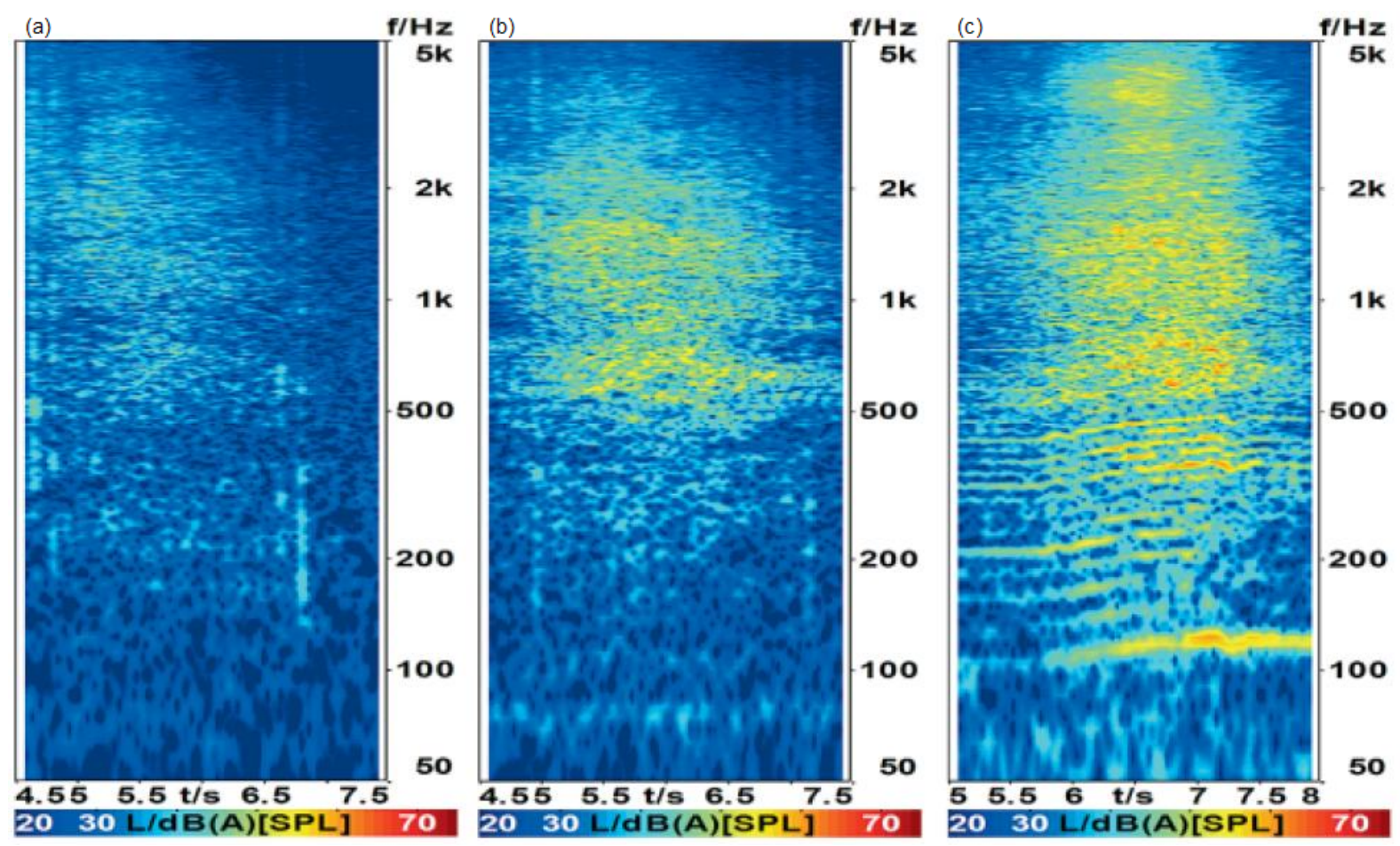

Fig. 7. Colourmap plots of different pass-by noise tests: (a) engine switched off and slick tyres; (b) engine switched off with standard tyres; (c) ISO 362 test [12] (reprinted from 'Alt N, Wolff K, Eisele G, Pichot F. Fahrzeugaussengeräuschsimulation (Vehicle exterior noise simulation). Automobiltechnische Zeitschrift 2006; 108:832-36.' With kind permission of Dr Alt). 


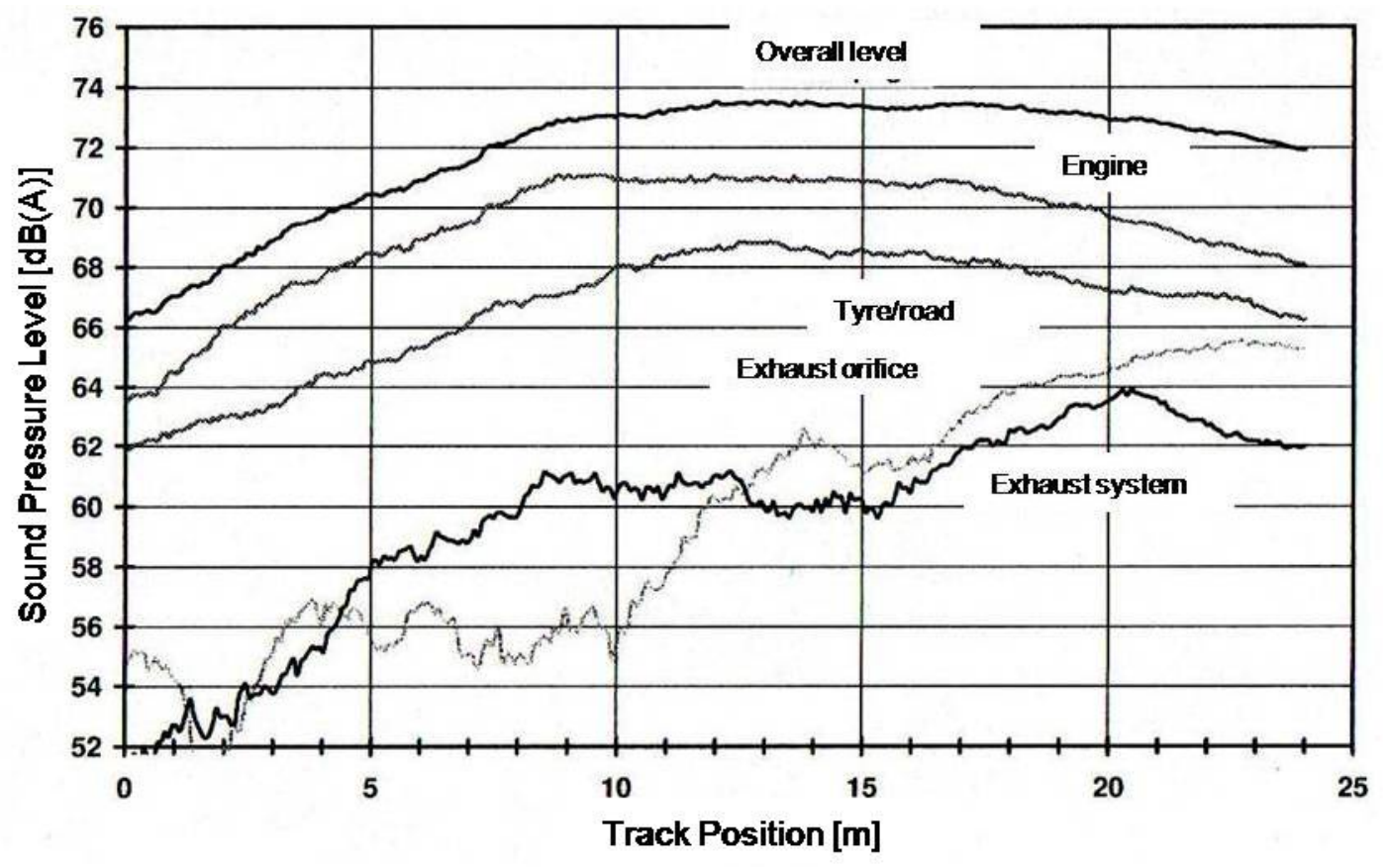

Fig. 8. Individual noise source contributions to the overall pass-by noise level [9] (reprinted from 'Biermann J-W. Geräuschverhalten von Kraftfahrzeugen (Noise characteristics of vehicles) - Lecture notes.' With kind of permission of Prof Biermann). 


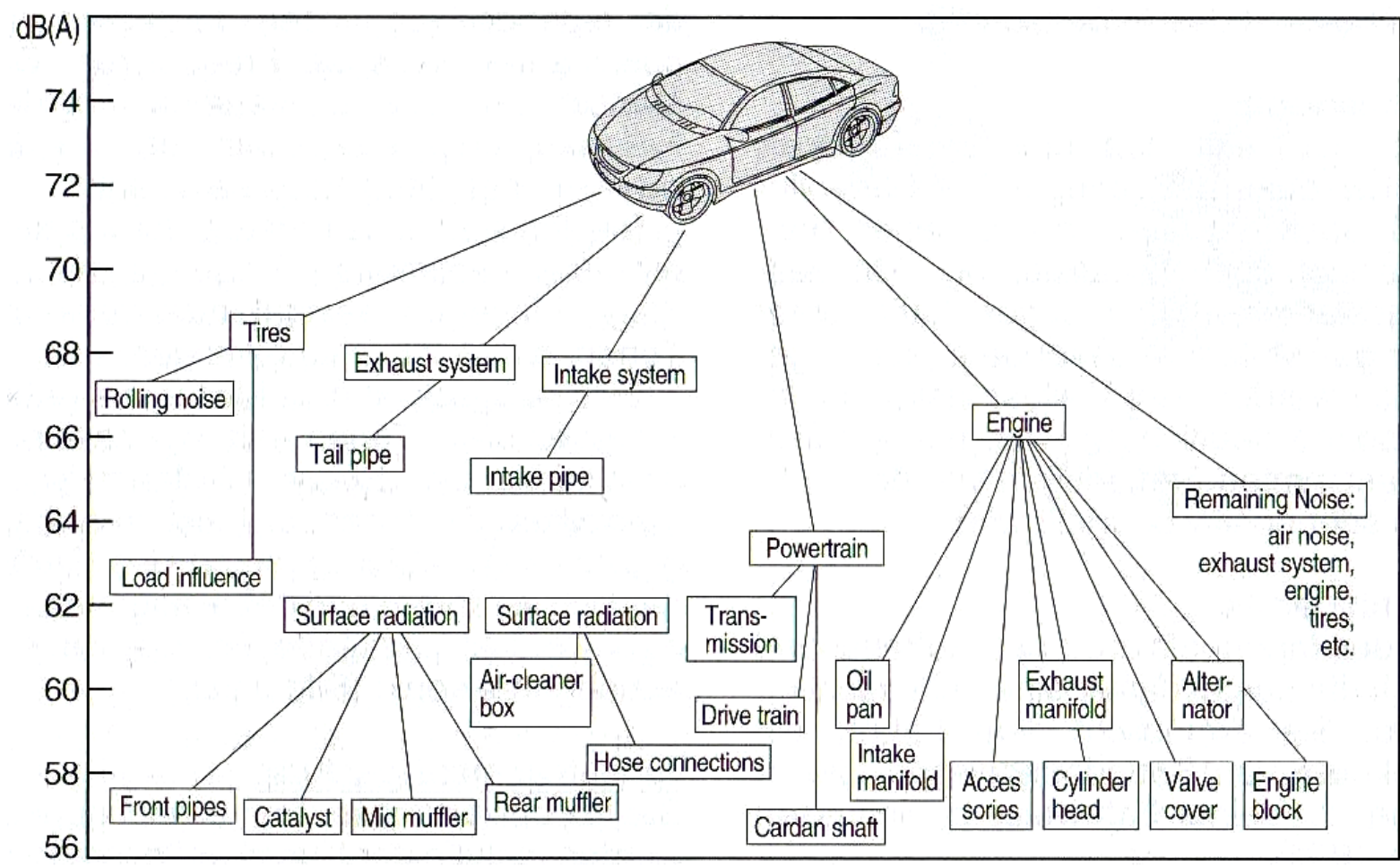

Fig. 9. Noise source ranking for a vehicle during the pass-by noise test [21] (reprinted from 'Bosch - Kraftfahrtechnisches Taschenbuch (Automotive Handbook). 25 $5^{\text {th }}$ ed. Wiesbaden: Vieweg+Teubner; 2004.' With kind permission of Robert Bosch $\mathrm{GmbH}$ ). 


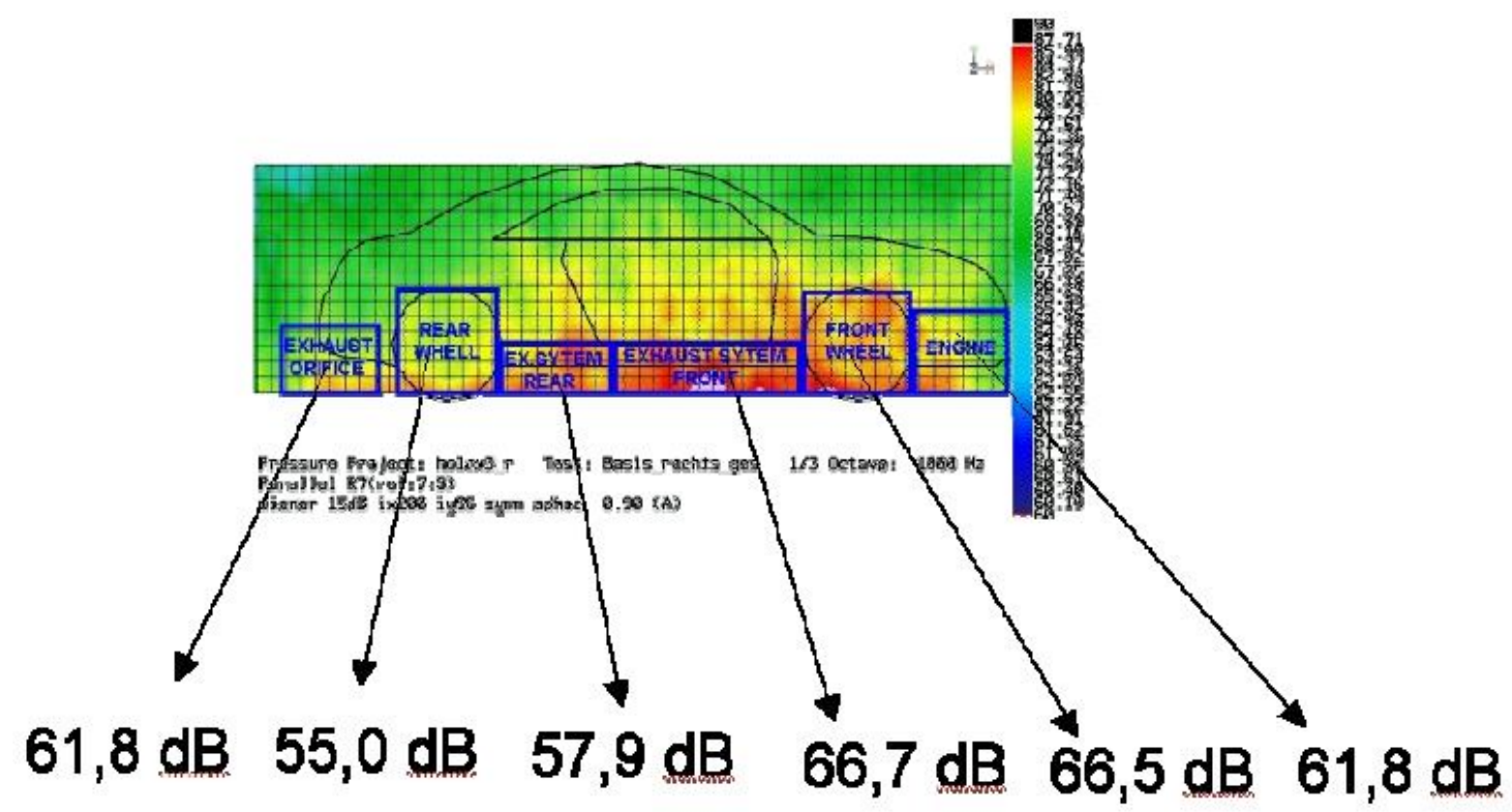

Fig. 10. Analysis of a stationary indoor pass-by noise test by means of Nearfield Acoustic Holography [15] (reprinted from 'Arndt R, Fliesser W, Rein D, Fankhauser C. Analysis of pass-by noise using Nearfield Acoustic Holography'. Copyright Virtual Vehicle Research Center. With kind permission of DEGA e.V. German Acoustical Society and Mr Arndt). 


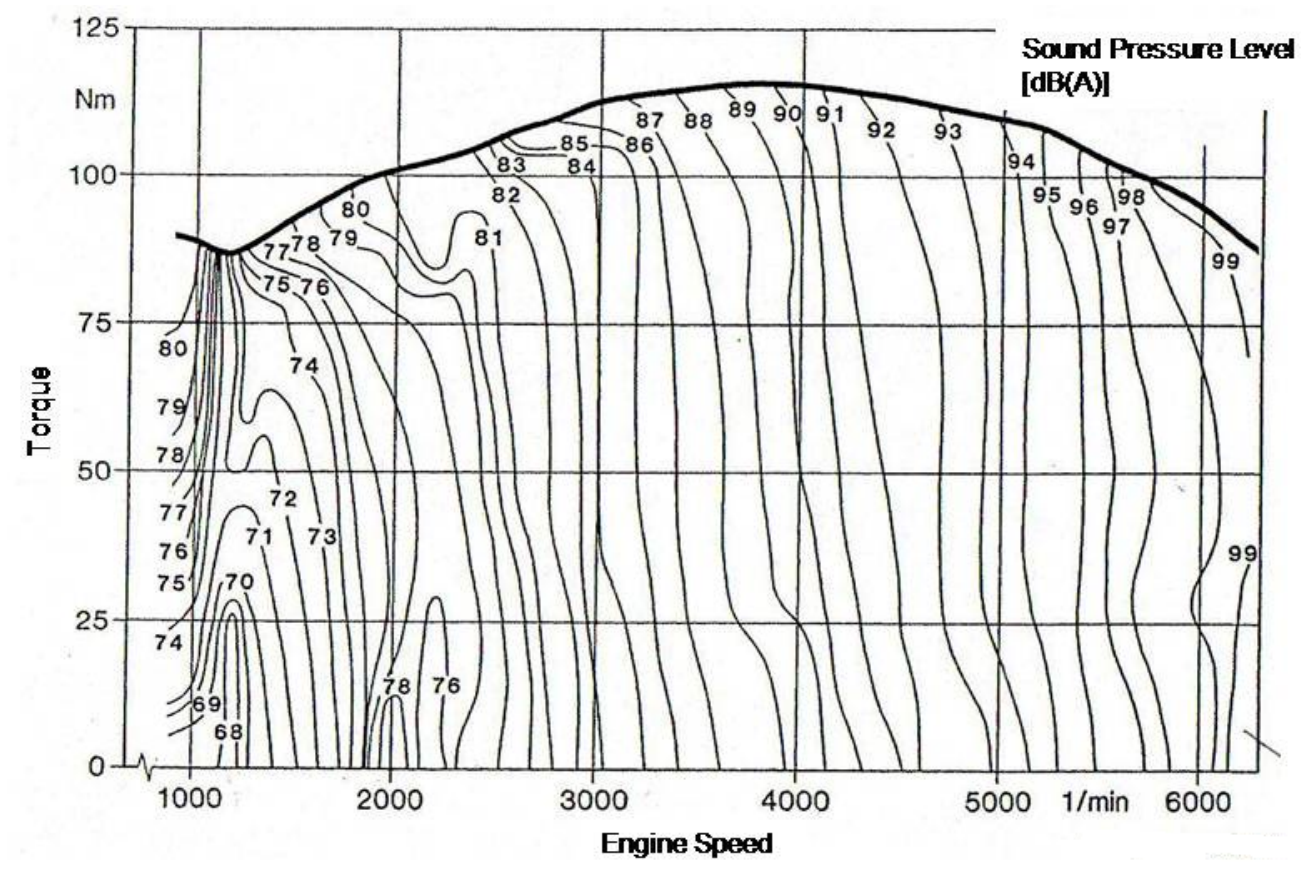

Fig. 11. Engine noise map of sound pressure level versus torque and rotational speed [9] (reprinted from 'Biermann J-W. Geräuschverhalten von Kraftfahrzeugen (Noise characteristics of vehicles) - Lecture notes.' With kind of permission of Prof Biermann). 


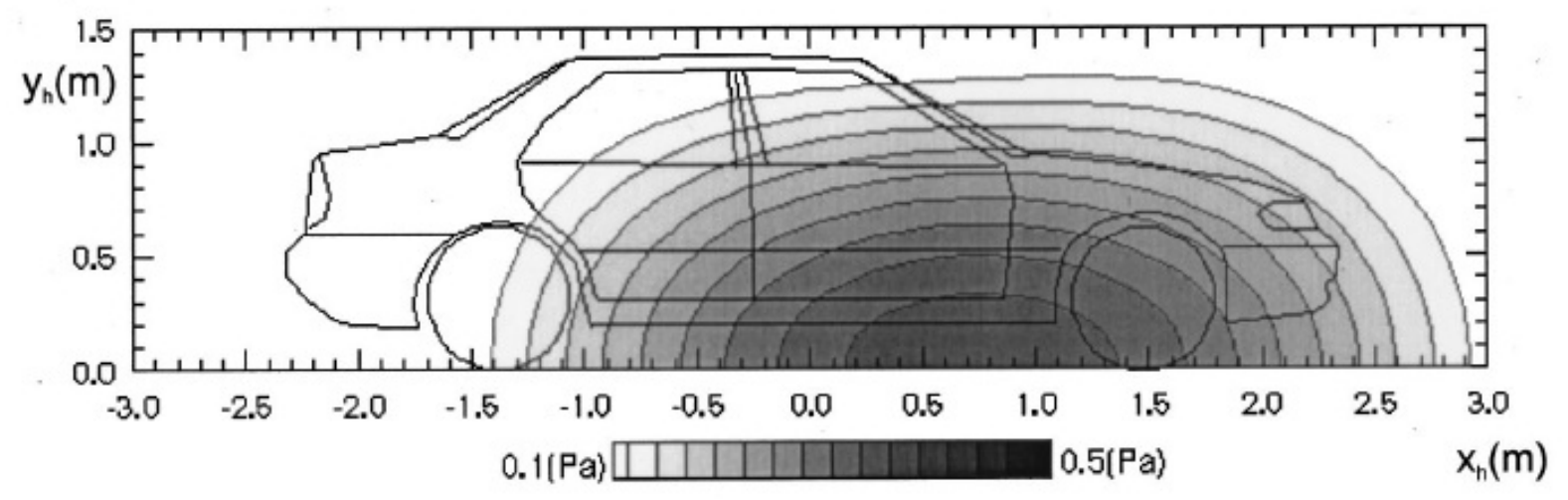

Fig. 12. Engine noise distribution on a measurement plane at $120 \mathrm{~Hz}$ [23] (reprinted with permission from 'Park S-H, Kim Y-H. Visualization of pass-by noise by means of moving frame acoustic holography. J Acoust Soc Am, vol. 110 pp. 2326-39 (2001)'). Copyright 2001, Acoustical Society of America. 


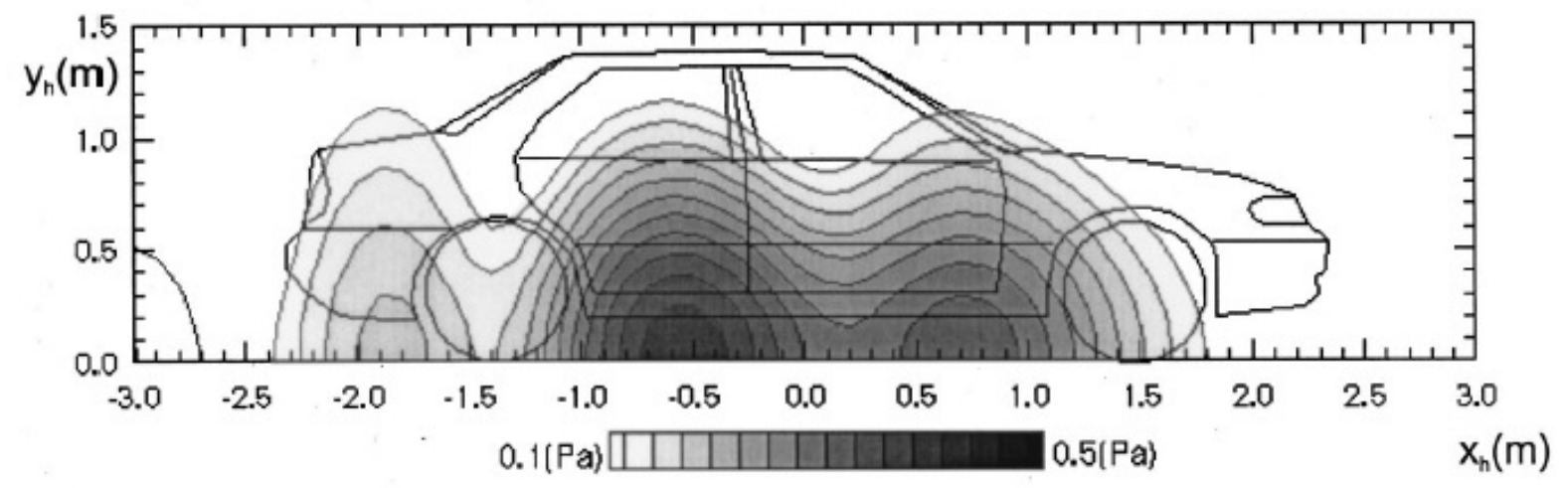

Fig. 13. Engine noise distribution on a measurement plane at $180 \mathrm{~Hz}$ [23] (reprinted with permission from 'Park S-H, Kim Y-H. Visualization of pass-by noise by means of moving frame acoustic holography. J Acoust Soc Am, vol. 110 pp. 2326-39 (2001)'). Copyright 2001, Acoustical Society of America. 


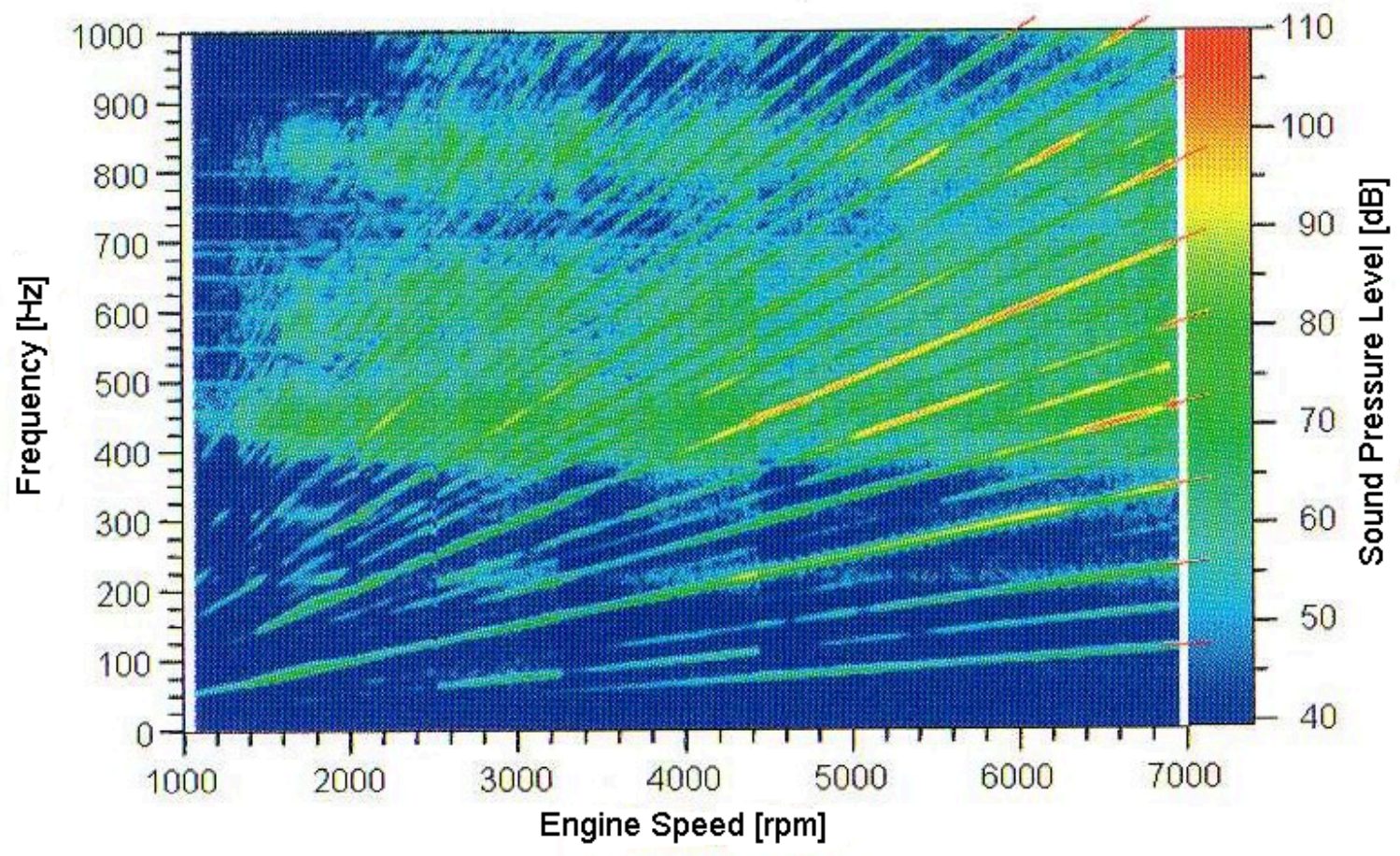

Fig. 14. Sound pressure level of intake orifice noise versus engine speed and frequency [13] (reprinted from 'Zeller P. Handbuch Fahrzeugakustik (Handbook Vehicle Acoustic).

Vieweg + Teubner Verlag; 2009'. With kind permission of Springer Science and Business Media). 

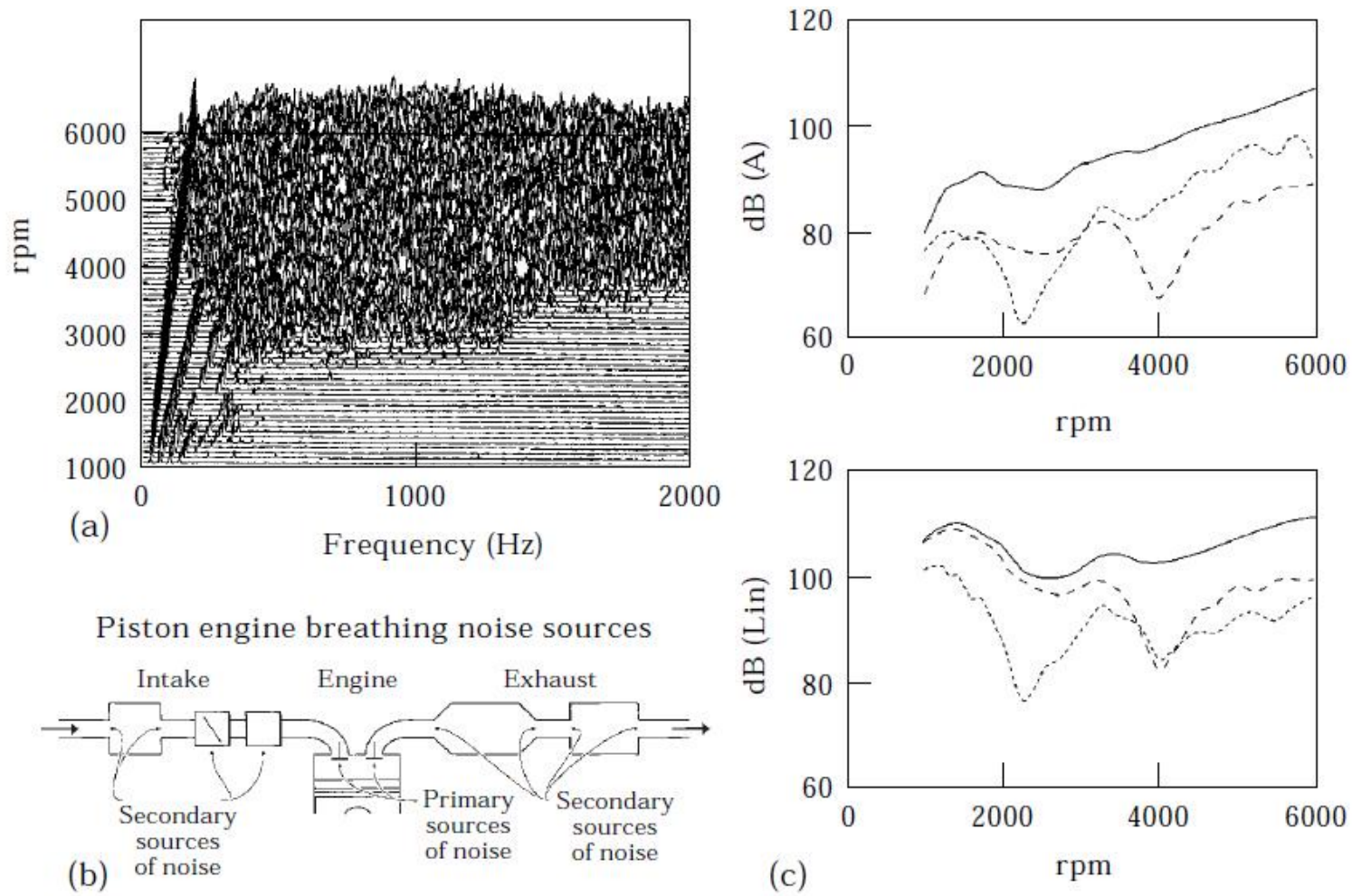

Fig. 15. Exhaust tailpipe emissions from a 4-cylinder 4-stroke engine: a) Waterfall plot; b) system schematic; c) A-weighted and unweighted dB spectra measured at $0.25 \mathrm{~m}$ and $45^{\circ}$ from the orifice (_ overall; ---2nd order; ... 4th order) [28] (reprinted from 'Davies P, Holland K. I.C. engine intake and exhaust noise assessment. Journal of Sound and Vibration 1999; 223:425-44.' With kind permission of Elsevier Ltd). 

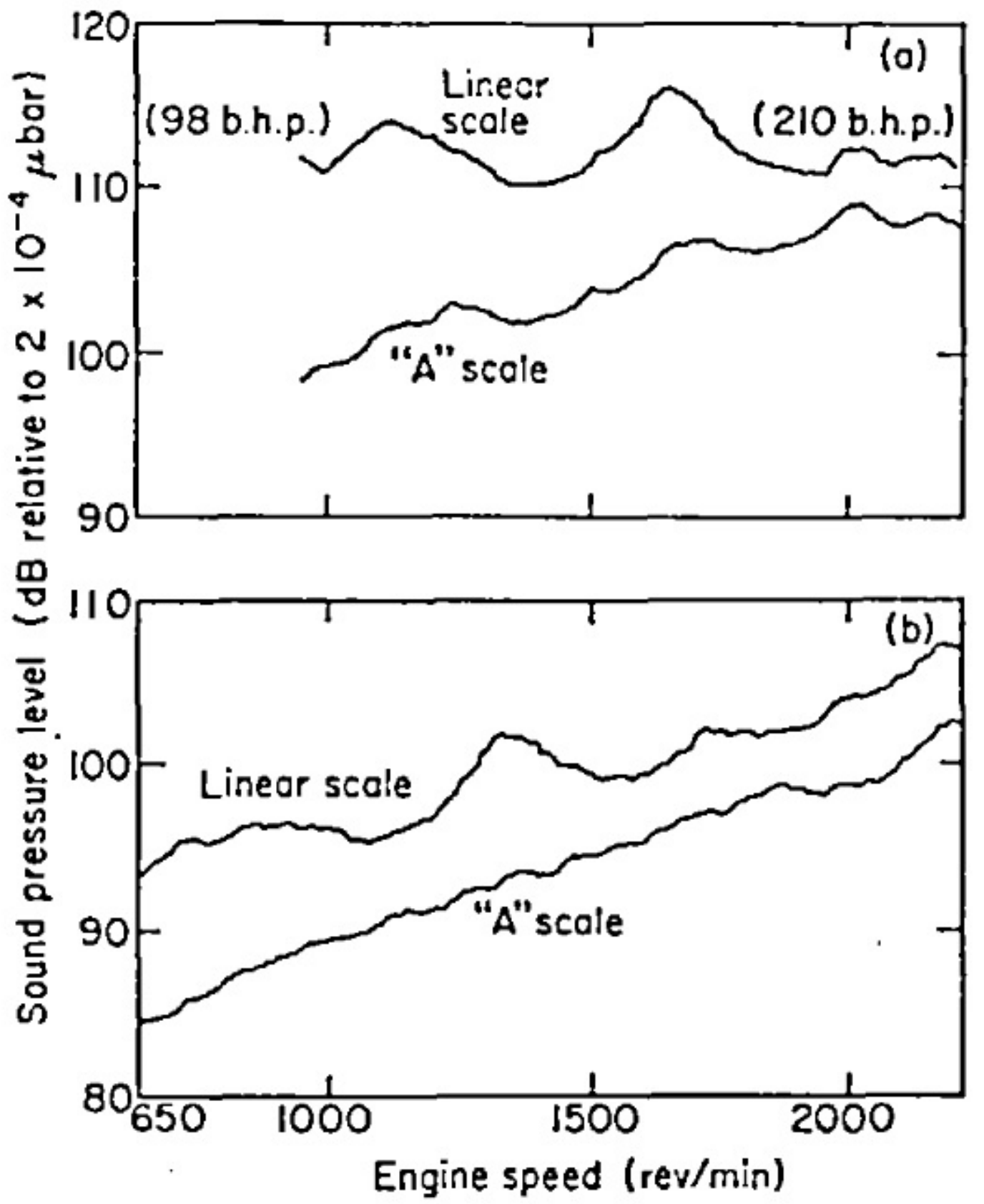

Fig. 16. Variation of exhaust noise with engine speed: a) full load; b) no load [31] (reprinted from 'Alfredson R, Davies $P$. The radiation of sound from an engine exhaust. Journal of Sound and Vibration 1970; 13:389-408.' With kind permission of Elsevier Ltd). 


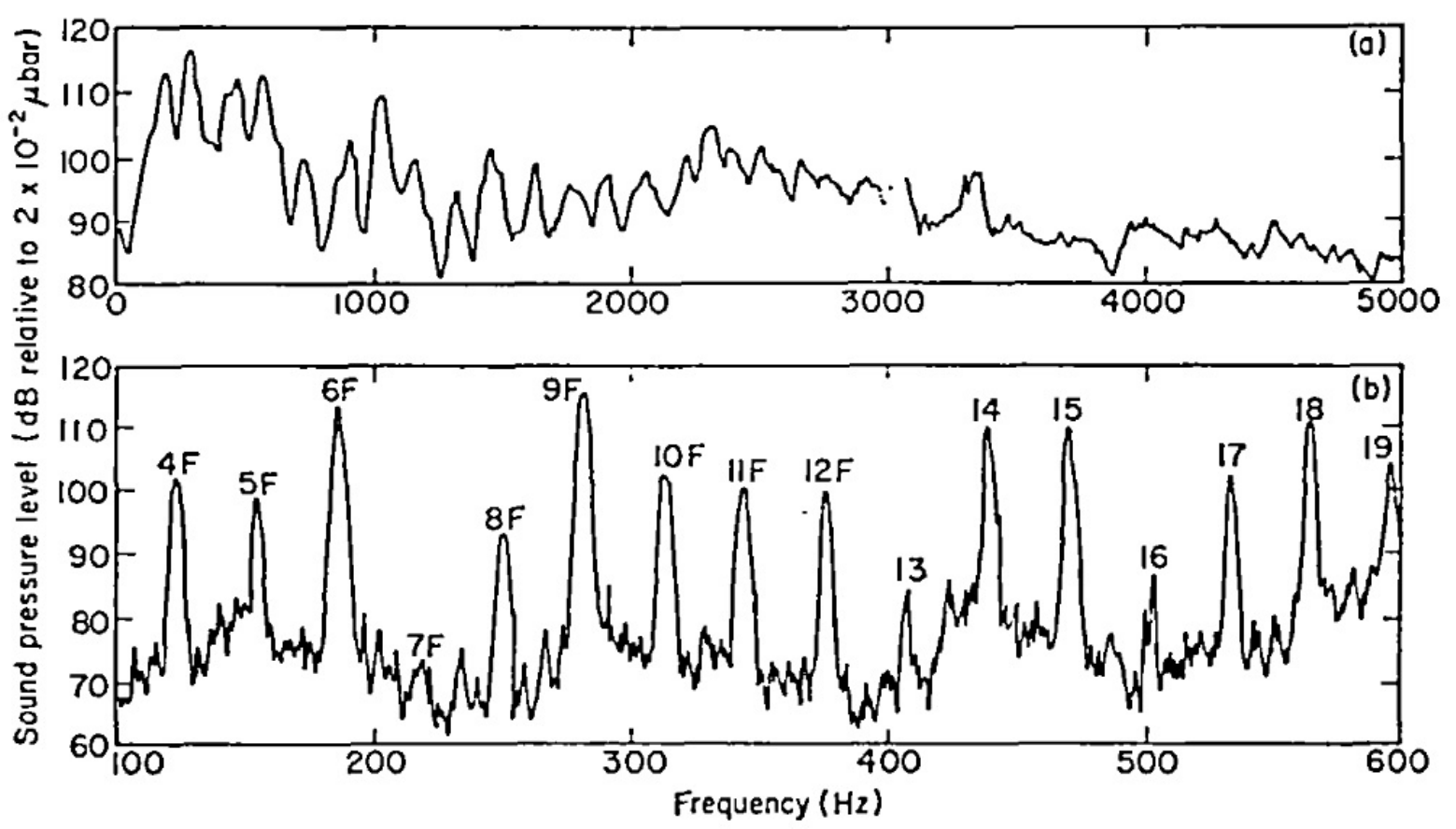

Fig. 17. Typical frequency spectrum of exhaust noise measured at 1880 r.p.m. and $0.9 \mathrm{~m}$ from the outlet: (a) 0-5000 Hz; (b) 100-600 Hz [31] (reprinted from 'Alfredson R, Davies P. The radiation of sound from an engine exhaust. Journal of Sound and Vibration 1970; 13:389-408.' With kind permission of Elsevier Ltd). 

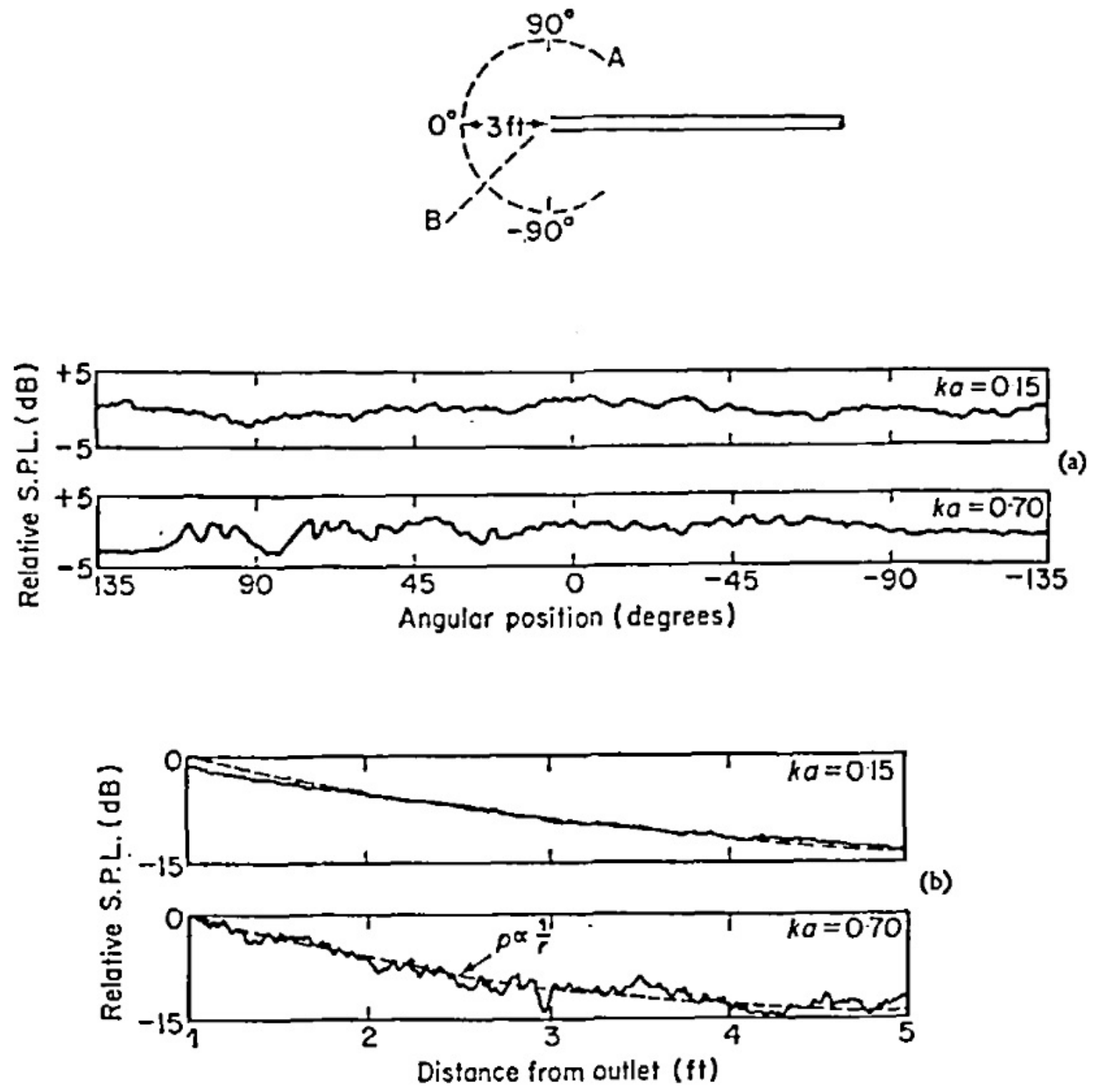

Fig. 18. Radiated sound characteristics of an exhaust orifice: a) directivity patterns along circular path 'A'; b) relation of sound pressure level to distance along radial path 'B' [31] (reprinted from 'Alfredson $\mathrm{R}$, Davies $\mathrm{P}$. The radiation of sound from an engine exhaust. Journal of Sound and Vibration 1970; 13:389-408.' With kind permission of Elsevier Ltd). 


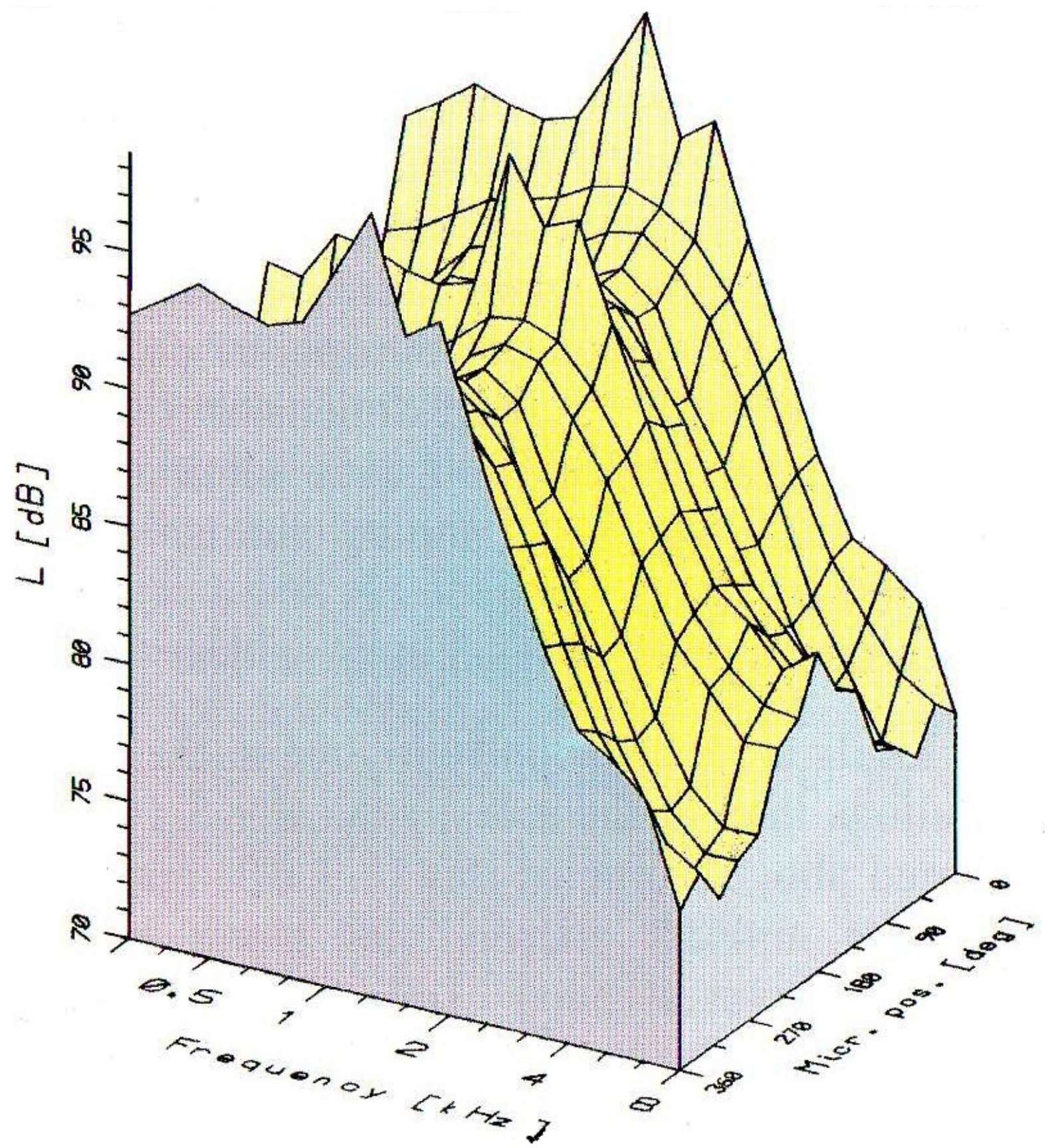

Fig. 19. Horizontal directivity of the tyre/road noise of a single tyre measured on a dynamometer drum at a radius of approximately $0.4 \mathrm{~m}$ around the tyre [8] (reprinted from 'Sandberg U, Ejsmont JA. Tyre/road noise reference book. Kisa (Sweden): Informex; 2002.' With kind permission of Informex HB). 


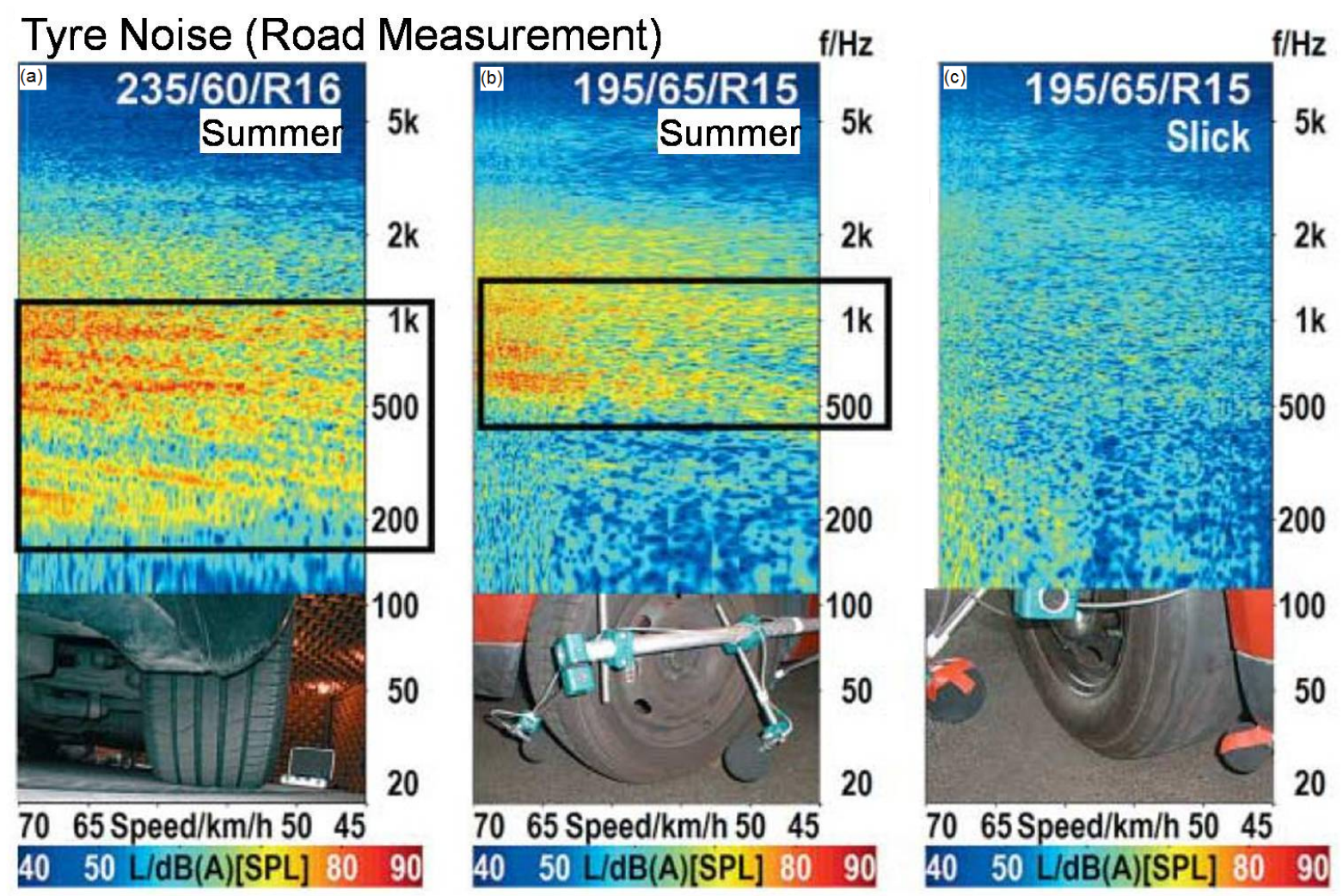

Fig. 20. Waterfall plots of tyre/road noise measured on the road with three different tyre types: (a) wide summer tyre; (b) regular summer tyre; (c) slick tyre [12] (reprinted from 'Alt N, Wolff K, Eisele G, Pichot F. Fahrzeugaussengeräuschsimulation (Vehicle exterior noise simulation). Automobiltechnische Zeitschrift 2006; 108:832-36.' With kind permission of Dr Alt). 


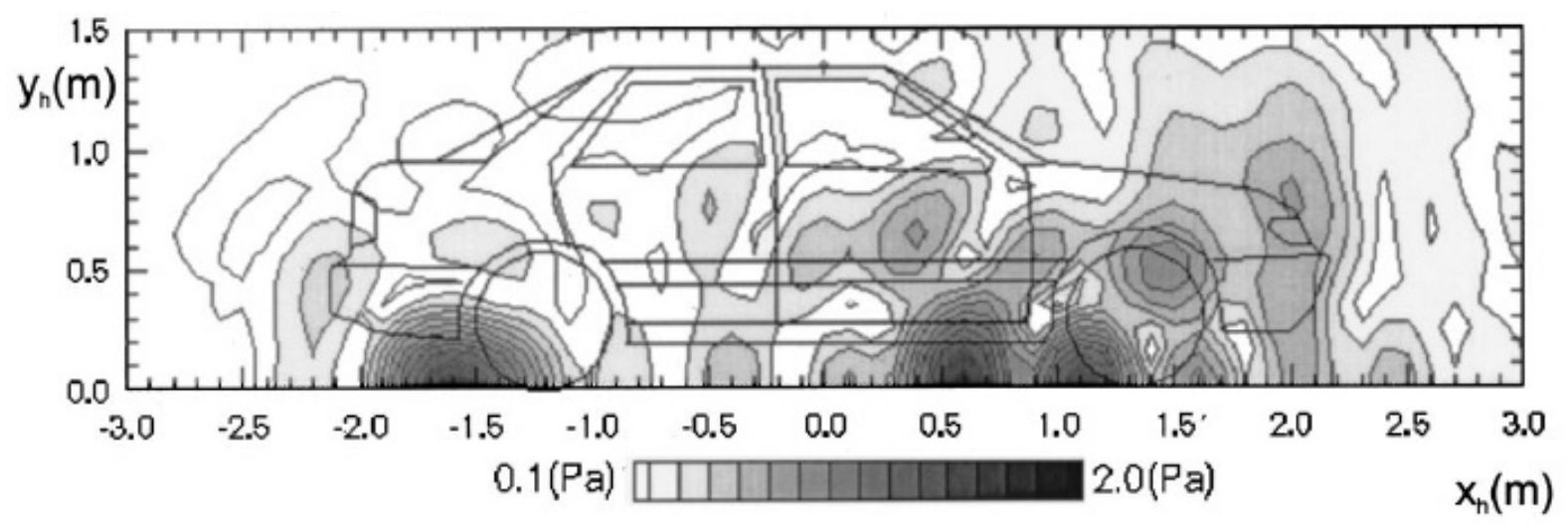

Fig. 21. Tyre/road noise distribution on a measurement plane at $474 \mathrm{~Hz}$ under accelerating condition according to ISO 362 [23] (reprinted with permission from 'Park S-H, Kim Y-H. Visualization of pass-by noise by means of moving frame acoustic holography. J Acoust Soc Am, vol. 110 pp. 2326-39 (2001)'). Copyright 2001, Acoustical Society of America. 


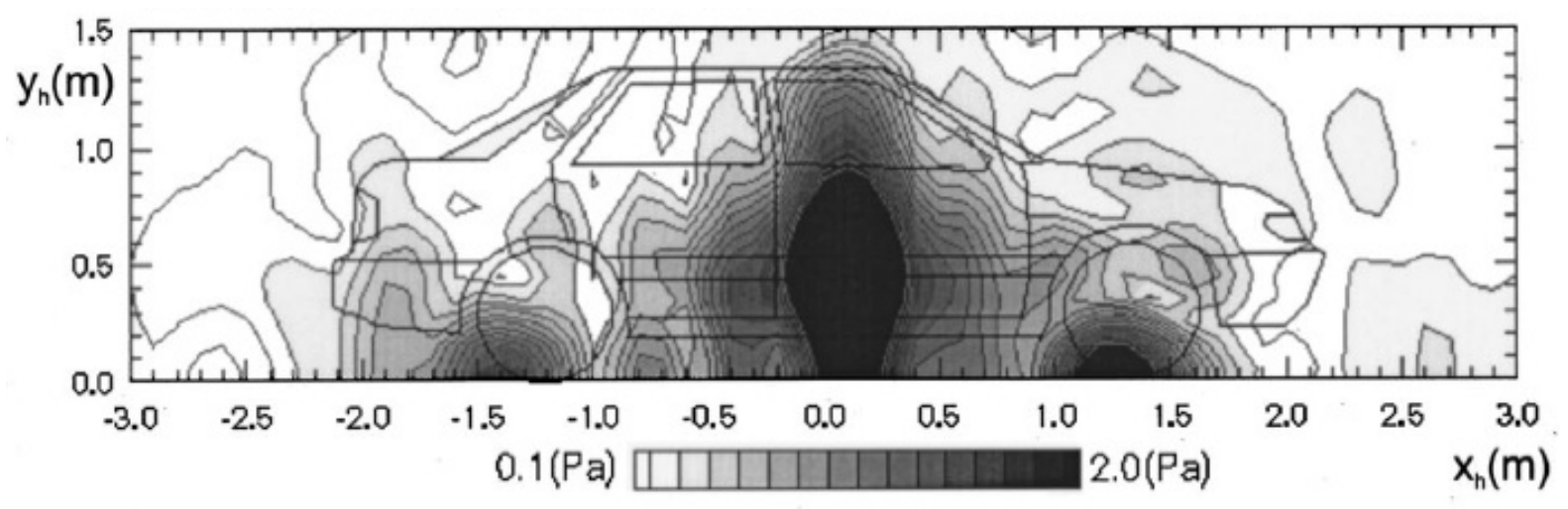

Fig. 22. Tyre/road noise distribution on a measurement plane at $500 \mathrm{~Hz}$ under constant velocity of 55 k.p.h. [23] (reprinted with permission from 'Park S-H, Kim Y-H. Visualization of pass-by noise by means of moving frame acoustic holography. J Acoust Soc Am, vol. 110 pp. 2326-39 (2001)'). Copyright 2001, Acoustical Society of America. 


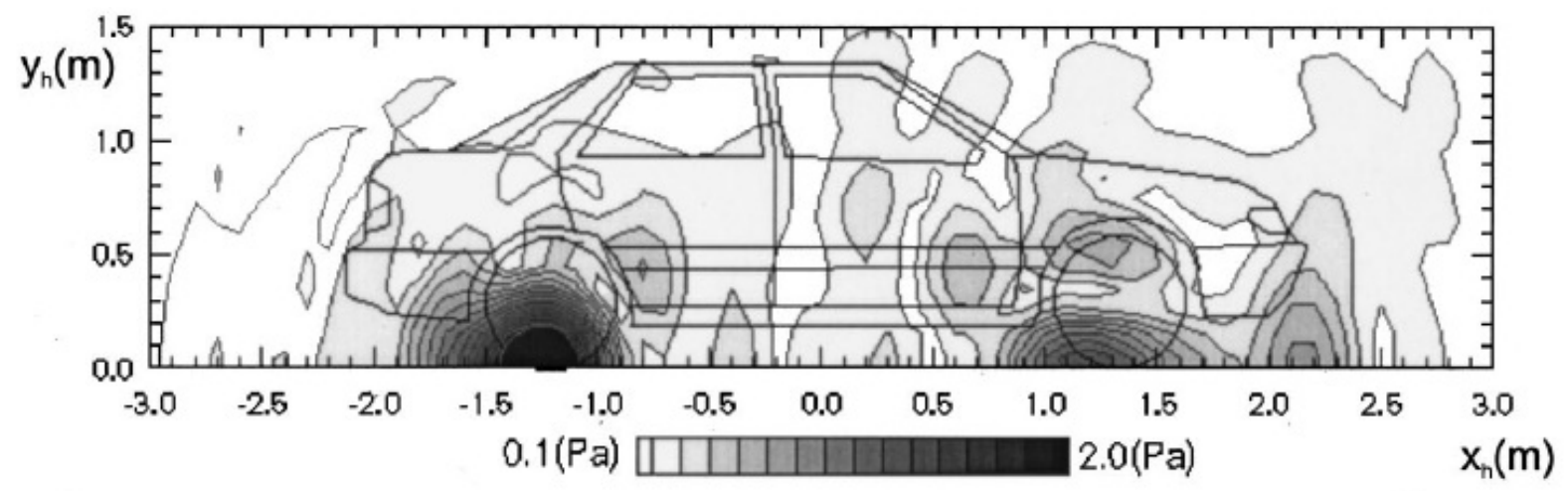

Fig. 23. Tyre/road noise distribution on a measurement plane at $486 \mathrm{~Hz}$ undercoast-down condition from 55 k.p.h. [23] (reprinted with permission from 'Park S-H, Kim Y-H.

Visualization of pass-by noise by means of moving frame acoustic holography. J Acoust Soc Am, vol. 110 pp. 2326-39 (2001)'). Copyright 2001, Acoustical Society of America. 


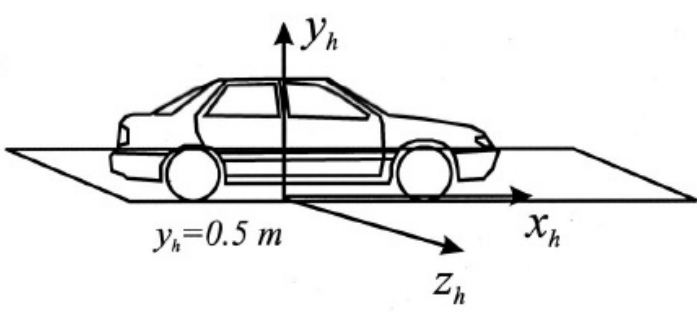

(a)

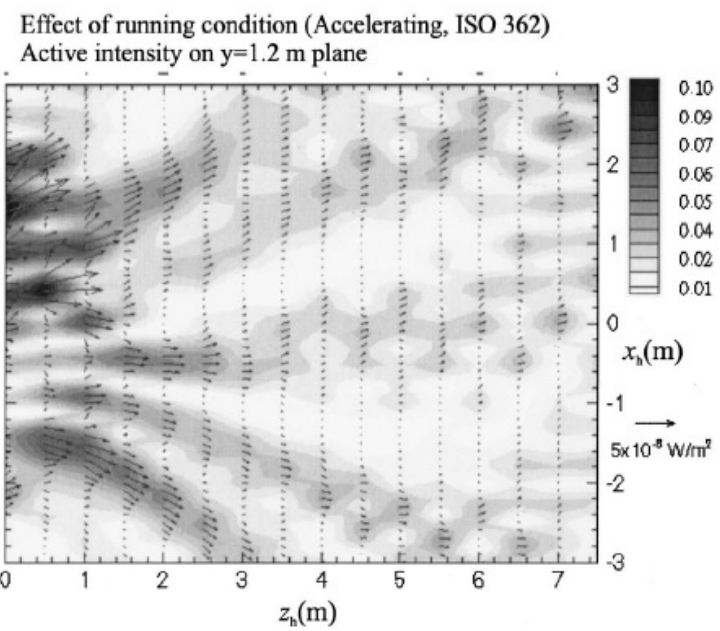

(c)

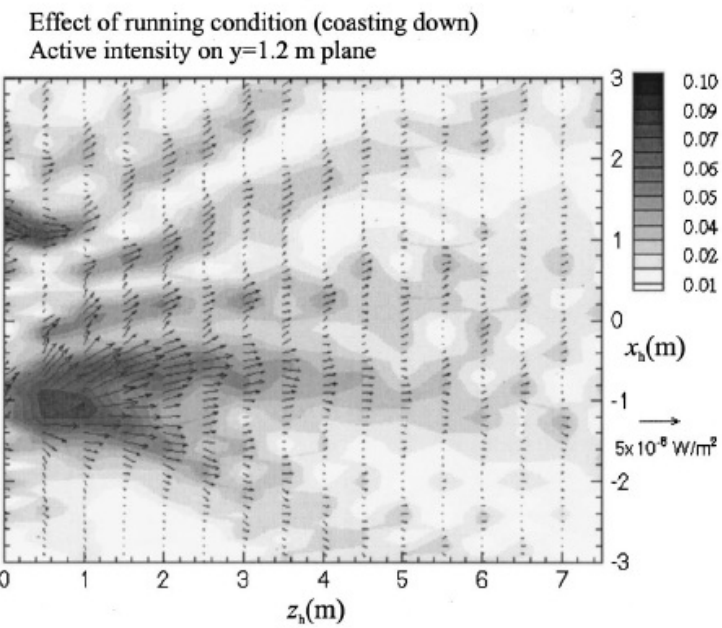

(d)

Fig. 24. Illustration of noise propagation in the far field by means of sound intensity: a) schematic representation of measurement plane $0.5 \mathrm{~m}$ above the ground level; b) result of constant speed test; c) result of acceleration test (ISO 362); and d) result of coast-down test [23] (reprinted with permission from 'Park S-H, Kim Y-H. Visualization of pass-by noise by means of moving frame acoustic holography. J Acoust Soc Am, vol. 110 pp. 2326-39 (2001)'). Copyright 2001, Acoustical Society of America. 